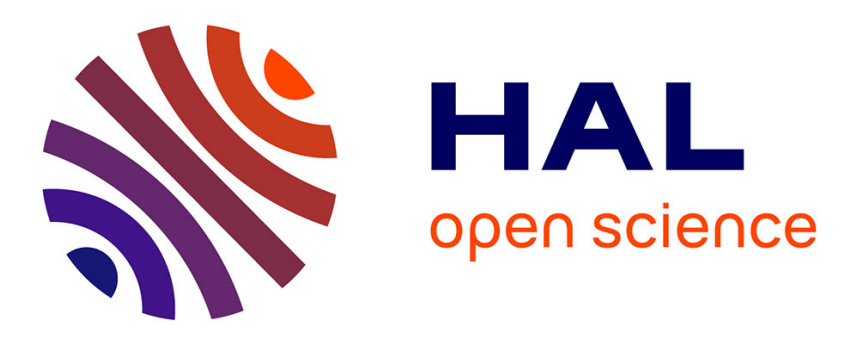

\title{
Flow in compound channel with abrupt floodplain contraction
}

Sébastien Proust, Nicolas Riviere, D. Bousmar, André Paquier, Y. Zech, R. Morel

\section{- To cite this version:}

Sébastien Proust, Nicolas Riviere, D. Bousmar, André Paquier, Y. Zech, et al.. Flow in compound channel with abrupt floodplain contraction. Journal of Hydraulic Engineering, 2006, 132 (9), pp.958970. 10.1061/(ASCE)0733-9429(2006)132:9(958) . hal-00274829

\section{HAL Id: hal-00274829 \\ https://hal.science/hal-00274829}

Submitted on 15 May 2020

HAL is a multi-disciplinary open access archive for the deposit and dissemination of scientific research documents, whether they are published or not. The documents may come from teaching and research institutions in France or abroad, or from public or private research centers.
L'archive ouverte pluridisciplinaire HAL, est destinée au dépôt et à la diffusion de documents scientifiques de niveau recherche, publiés ou non, émanant des établissements d'enseignement et de recherche français ou étrangers, des laboratoires publics ou privés. 


\title{
FLOW IN COMPOUND CHANNEL WITH ABRUPT FLOOD PLAIN CONTRACTION
}

\author{
S. Proust ${ }^{1}$, N. Rivière ${ }^{2}$, D. Bousmar ${ }^{3}$, A. Paquier ${ }^{4}$, Y. Zech $^{5}$, R. Morel $^{6}$
}

\begin{abstract}
:
Flooding rivers usually present transition reaches where the floodplain width can significantly vary. The present study focuses on an abrupt floodplain contraction (mean angle $22^{\circ}$ ) in order to determine whether one-dimensional (1D) models, developed for straight and slightly converging geometry, are equally valid for such a geometry. Experiments on a contraction model were carried out in an asymmetric compound channel flume. Severe mass and momentum transfers from the floodplain towards the main channel were observed, giving rise to a noteworthy transverse slope of the water surface and different head loss gradients in the two subsections. Three 1D models and one 2D simulation were compared to experimental measurements. Each 1D model incorporates a specific approach for the modeling of the momentum exchange at the interface boundary between the main channel and the floodplain. The increase of the lateral mass transfer generates moderate errors on the water level values but significant errors on the discharge distribution. Erroneous results arise because of incorrect estimations of both momentum exchange due to lateral mass transfers and boundary conditions which are imposed by the tested 1D models.
\end{abstract}

CE Database subject headings : Open channels; Nonuniform flow; Flood plains; Experimental data; Numerical models; Mass transfer; Contraction.

\footnotetext{
${ }^{1}$ Researcher, Hydrology-Hydraulics unit, Cemagref Lyon, Quai Chauveau, 3bis, CP 220 - 69336 Lyon Cedex 09, France. E-mail: proust@lyon.cemagref.fr.

${ }^{2}$ Assistant Professor, LMFA, INSA de Lyon, Av. Einstein, 20, 69621 Villeurbanne Cedex, France. E-mail: riviere@insa-lyon.fr.
} 
${ }^{3}$ Formerly Postdoctoral Researcher, Fond National de la Recherche Scientifique; Now Engineer, Laboratory of Hydraulic Research (D.213), Ministère wallon de l'Equipement et des Transports, Rue de l'Abattoir, 164, 6200 Châtelet, Belgium. E-mail: dbousmar@met.wallonie.be..

${ }^{4}$ Researcher, Hydrology-Hydraulics unit, Cemagref Lyon, Quai Chauveau, 3bis, CP 220 - 69336 Lyon Cedex 09, France. E-mail: paquier@1yon.cemagref.fr.

${ }^{6}$ Professor, Dept. of Civil and Environmental Engineering, Hydraulics Unit, Université catholique de Louvain, Place du Levant, 1, 1348 Louvain-la-Neuve, Belgium. E-mail: zech@gce.ucl.ac.be.

${ }^{6}$ Professor, LMFA, INSA de Lyon, Av. Einstein, 20, 69621 Villeurbanne Cedex, France. E-mail: robert.morel@insa-lyon.fr.

\section{INTRODUCTION}

In the computation of water profile and discharge distribution of overbank flow in rivers, the transition reaches require special attention. Indeed, they are the place of significant mass exchanges between subsections that give birth to noteworthy 3D physical phenomena. $2 \mathrm{D}$ or $3 \mathrm{D}$ simulations can logically be appropriate for such reaches. However, this paper emphasizes on one-dimensional models since they are still widely used for backwater computations and flood plain discharge calculation when modeling a complete river system. Thus, from an engineering point of view, it seems necessary to test the relevance of classical 1D models for transition reaches, to identify the most restrictive assumptions of such models, and to evaluate the opportunity of a specific treatment. It should be noted that such models have shown their effectiveness for non-prismatic compound channel when mass transfers are moderate.

Most previous experiments in compound channels have been performed under uniform flow conditions in straight floodplains, with prismatic or meandering main channels (see e.g. Shiono and Knight 1991, Wormleaton and Merrett 1990, Sellin et al. 1993, Abril and Knight 2004, Martin-Vide et al. 2004). Particularly, studies based on the data collected in the large scale Flood Channel Facility, H.R. Wallingford, U.K., are mainly focused on the conveyance evaluation, the flow pattern description in the composite section, and the bed shear stress 
distribution (Knight et al. 1994). Flow-width transitions were not often explored except for bridges across floodplains, and mostly in the case of single channel (Hunt et al. 1999). Only few studies were devoted to non-prismatic floodplain flows: Bousmar et al. (2004) with two symmetrical narrowing floodplains (angle between $3.8^{\circ}$ and $11.3^{\circ}$ ); Elliot and Sellin (1990) with the case of skewed flows in a compound channel (skew angle of $2^{\circ}, 5^{\circ}$ and $9^{\circ}$ ); Jasem (1990) for similar skewed flows but at a smaller scale; Sturm and Janjua (1994) with a groyn in the floodplain focusing on scouring. The present study of the flow in an abrupt floodplain contraction (mean angle $22^{\circ}$ ) extends those previous works to more rapidly varied conditions.

Experimental data were collected in an asymmetric compound channel flume at the laboratory of the Compagnie Nationale du Rhône, Lyon, France (Fig.1). The flow structure is characterized by: (1) a domination of the mass exchanges compared to turbulent transfers; and (2) the presence of secondary current cells in the main channel. The overbank flow rolls over the inbank one, inducing a horizontal shear and associated secondary-current cells as observed in skewed or meandering compound channels (Shiono \& Muto 1998). A notable transverse water surface slope appears at the approach to the end of the converging reach, in relation with the mass transfer between both beds. The coexistence of supercritical flow in the floodplain and subcritical flow in the main channel is also observed in this area. Eventually, the evolution of the subsection-averaged head, as defined by Yen (2002), is different from the main channel to the floodplain.

Considering such a flow, the attention is focused on the ability of 1D-approaches with different levels of complexity to model physical phenomena. Notably, relations validated for symmetrically narrowing floodplains (Bousmar 2002, Bousmar et al. 2004) are evaluated in this configuration.

First, experimental values of the main hydraulic parameters are presented and analyzed. Then, different 1D modellings of interfacial exchanges between the main channel 
and the floodplain are exposed and compared to experimental results. Each approach has a specific treatment of the interfacial transfers: (1) the classical Divided Channel Method (DCM) used by HEC-RAS ignores the momentum transfer through subsection boundaries; (2) the Exchange Discharge Model (EDM), implemented in the program Axeriv, accounts for both mass and turbulent exchanges (Bousmar and Zech 1999); (3) and the Debord Formula, used in the program Talweg-Fluvia, proposes an empirical correction of the DCM that merely models the turbulent transfer (Nicollet and Uan 1979). Then, 2D calculations are performed with the program Mac2D (Bousmar 2002), in order to shed light on the phenomena that are not taken into account by those 1D-approaches. Notably, 1D and 2D head loss gradients are compared.

This analysis helps to understand the calculated water profiles and discharge distribution evolution, obtained by Hec-RAS, Talweg-Fluvia, and Axeriv.

\section{EXPERIMENTAL SET-UP AND MEASURING TECHNIQUES}

New experiments were performed in a compound channel flume of length $L=13 \mathrm{~m}$ and total width $B=2.97 \mathrm{~m}$, with a bed slope $S_{0}=1.9 \times 10^{-3}$ (Fig. 1 and 2). As this set-up was primarily used to reproduce an existent river dynamics, it exhibited a slight curvature, with an approximate radius $25 \mathrm{~m}$. The reference $x y z$ was defined with $x$-axis always parallel to the right side of the flood plain. The bed was cement covered with different ridges orientated so as to obtain different surface roughness in the main channel and in the floodplain. The bankfull depth was $0.16 \mathrm{~m}$ deep below the flood plain level, while its bottom width was $B_{m c}=$ $0.7 \mathrm{~m}$. The bank presented a constant slope of $32^{\circ}$ between the main channel and the floodplain. The floodplain width was $B_{f p}=2.17 \mathrm{~m}$. An obstacle was set on the floodplain (Fig. 1 and 2), presenting a strong convergence of length $350 \mathrm{~cm}$ and of projected width 143 
$\mathrm{cm}$ perpendicularly to the main flow direction (mean angle of $22^{\circ}$ ). The flow was studied between $x=0$ and $4.5 \mathrm{~m}$.

A stilling basin preceded the entrance of the compound channel, and the flow stilling was achieved by honeycombs of bricks and wire netting buffers. Due to the small length to width ratio $L / B$, particular attention was devoted to supply the channel with a discharge distribution between subsections close to the one observed in uniform flow conditions (Proust et al. 2002, Bousmar et al. 2005). For this purpose, the inlets of the two channels were separated in the stilling basin. A sharp-crested weir was placed at the inlet of the floodplain in order to limit its discharge $Q_{f p}$ compared to the main channel discharge $Q_{m c}$ for a given depth in the basin. At the downstream end of the channel, an inclined gate was used to set a constant water depth in uniform-flow conditions. Two discharges were investigated during the experiments to highlight the influence of the relative water depth (See- Tab. 1).

Water levels were measured by a moveable point gauge. The accuracy was $\pm 0.15 \mathrm{~mm}$, but could worsen to $\pm 0.3 \mathrm{~mm}$ in areas where the surface was strongly perturbed (i.e. in the vicinity of the obstacle and just after the stilling basin). Velocities were measured using a miniature propeller of $1 \mathrm{~cm}$ diameter for the lower discharge; and an acoustic Doppler Velocimeter (Nortek NDV 2D-3D side-looking probe) for the larger one. In addition to the propeller measurements, the main deviation of the velocity to the $x$-direction was measured using a homemade miniature vane, with an accuracy of about $\pm 2^{\circ}$. Depth-averaged velocities were obtained from 4 measurements on each vertical in the main channel, and from 3 measurements in the flood plain. Four vertical profiles were recorded in the main channel, and between 4 and 10 in the floodplain (Fig.4) in order to determine the depth-averaged velocity distribution. The subsection and total discharges were estimated by integration of the velocities on cross-section areas. The so-estimated total discharges were found to be within - 
$1 /+6 \%$ of the discharge measured by an electromagnetic flowmeter installed on the supply pipe.

The roughness coefficient values were calibrated from uniform flow conditions. Seven uniform flows were obtained in the main channel, and two in the floodplain, by separating both subsections by a wall at the interface. Using the Manning formula leads to roughness values of 0.0119 and $0.0132 \mathrm{~s} / \mathrm{m}^{1 / 3}$ in the main channel and in the floodplain, respectively. The associated sand grain roughness $k_{s}=0.0006$ and $k_{s}=0.0014 \mathrm{~mm}$, correspond to values between concrete class 3 and class 4 (French 1985, Tab. $4.1 \mathrm{p} \mathrm{116).} \mathrm{The} \mathrm{same} \mathrm{roughness}$ values were used for the flow in the abrupt floodplain. The large values of Reynolds numbers (from 16000 to 170000 ) at any studied station $x$ of the whole reach assure a fully rough turbulent flow in both subsections, and a Manning roughness coefficient independent of the hydraulic radius $R_{h}$ (French 1985).

\section{EXPERIMENTAL RESULTS}

In order to test the relevance of 1D models for non-prismatic compound channels, the flow configuration was designed to enhance the longitudinal variations of the hydraulic parameters. This should enable the assessment of methods developed for slightly nonprismatic compound channels. In order to discuss the standard 1D assumptions, some variables such as subsection-averaged values (water depths, velocities, discharges, onedimensional head) were defined in spite of the flow heterogeneity, especially in the floodplain. Their relevance is discussed below.

\section{Water levels}

The transverse water level distribution is given for the higher discharge, $Q=260 \mathrm{l} / \mathrm{s}$, on Fig 3. Due to the contraction abruptness and the centrifugal effects, transverse gradients of these levels are observed for $x=4.5 \mathrm{~m}$, with differences in the range $20-25 \%$ of the 
floodplain mean flow depth for $Q=150$ and 260 1/s. It is important to notice that the channel curvature influence, measured in uniform flows conditions, is of a lower magnitude order. Consequently, the longitudinal water surface slopes are different from subsection to subsection at the approach to the end of the converging reach. The drop of the free surface level along the $x$-axis can also be related to the velocities increase. Variations of the relative flow depth $h_{r=} h_{f p} / h_{m c}$ are presented in Tab.1

\section{Velocity field}

The transverse distribution of depth-averaged velocity components are presented on Fig. 4: $U_{d}$ is the longitudinal component, and $V_{d}$, the transverse one. As part of the flow is forced to leave the floodplain, a transverse current develops, and downstream, the velocities become constant across the section width due to the contraction for the higher discharge. In the upper part of the reach, the velocity gradient between the main channel and the floodplain is less noticeable for $Q=260 \mathrm{l} / \mathrm{s}$ than for the lower discharge, due to the higher relative flow depth $h_{r}$. Fig. 5 presents the lateral $v$-and vertical $w$-components of velocities, measured for the higher discharge, at the station $x=3.5 \mathrm{~m}$. The overbank flow rolls over the inbank one towards the main channel bank opposite to the floodplain. This generates an helical motion that increases along the $x$-axis. The flow pattern-direction in the main channel close to the bottom (at $0.2 h_{m c}$ ) is thus different from the one close to the surface (Fig.6). This flow structure presents similarities with the one observed in the main channel of slightly narrowing (Bousmar et al. 2004), skewed (Elliot \& Sellin 1990) or meandering (Shiono \& Muto 1998) compound channels.

\section{Discharge distribution}

The evolution of the discharge distribution along the studied reach is presented on Fig. 7, through the discharge floodplain as percentage of the total discharge $Q_{f p} / Q$ (x 100). 
Between $x=0$ and $x=4.5 \mathrm{~m}, 75 \%$ and $54 \%$ of the floodplain discharge is transferred to the main channel for the lower and higher discharges respectively.

\section{Head evolution}

A subsection-averaged head, $H_{\text {sub }}$, can be defined in the $x$-direction, accounting for transverse variations of $u$ and $v$-components of local velocity (Lancastre 1999) and water levels $Z(y)$ from an eulerian point of view.

$H_{\text {sub }}=\frac{\iint_{A_{\text {sub }}} Z(y) u d A}{\iint_{A_{\text {sub }}} u d A}+\frac{\iint_{A_{\text {sub }}} \frac{\left(u^{2}+v^{2}\right)}{2 g} u d A}{\iint_{A_{\text {sub }}} u d A}$

where $Z(y)=Z_{b}+h(y), Z_{b}=$ bed level above reference datum, and $d A=d z . d y$. The total head, $H$, is defined in a same way on the whole cross-section area. The experimental head profiles computed in the whole cross-section, in both subsections are shown on Fig. 8. The influence of $v$-components is experienced on the total head $H$.

Noticeable differences on the head evolution are observed on the three profiles, for both discharges. This is due to a different evolution of the kinetic energy term in (1) along the channel in both subsections, in addition to a different evolution of water levels near the end of the converging reach. This could make inconsistent the 1D models that assume the same head evolution in all subsections when transfers between subsections are moderate. These models suggest that a river adjusts its energy budget along the flow (Bousmar and Zech 1999). As mass transfers become severe in the present abrupt contraction, this equality is not true any longer. This statement confirms previous assumptions by Yen (2002), that were not yet verified using experimental data. Accordingly, the flow can not adjust its energy budget within the whole cross-section when mass and energy transfers increase, because of inertial phenomena. A delay is also identified between the mass transfer and the water surface lateral inclination for both discharges: at station $x=3.5 \mathrm{~m}$ where the measured mass exchanges are 
the most significant (Fig. 4, $V_{d}$-components), the transverse water surface is horizontal, contrarily to the situation for $x=4.5 \mathrm{~m}$ (Fig. 3).

Secondly, a slight influence of $v$-components on the total head $H$ is observed for the higher discharge.

Eventually, as most 1D models consider a unique water level across the whole section of the compound channel, the influence of such a simplification on the subsection head evolution had to be assessed. The interaction between lateral and longitudinal gradients of the water levels is exposed in Rivière et al. (2002) and found significant. It generates an overestimation of the head slope in the main channel and in the whole section. It would thus introduce in that context a noteworthy redistribution of energy between subsections close to the end of the converging reach. This is a possible cause of errors in the prediction of hydraulic parameters by the $1 \mathrm{D}$ models, if computation starts from the downstream part of the reach.

\section{Froude numbers}

Noticeable differences can be observed between the one-dimensional Froude numbers estimated in each subsection of the compound channel. For both discharge rates, a juxtaposition of supercritical flow conditions in the floodplain and subcritical flow conditions in the main channel appears in the downstream part of the reach, between $x=3.5$ and $4.5 \mathrm{~m}$. At the narrowest section $(x=4.5 \mathrm{~m})$, for $Q=260 \mathrm{l} / \mathrm{s}$ (resp. $150 \mathrm{l} / \mathrm{s})$, one gets $: F r_{m c}=0.67$ (resp. 0.7) in the main channel, and $F r_{f p}=1.22$ (resp. 1.3) in the floodplain. 


\section{MODELLING OF INTERFACIAL TRANSFERS}

\section{Presentation of the different 1D models}

The relevance of 1D-approaches for compound channel is related to the accuracy of interfacial transfer modeling. The significance of these interfacial shear stresses and lateral discharges between subsections was investigated for backwater profiles computation in straight compound channel (Yen 1984, Yen et al. 1985), and more recently for slightly nonprismatic geometries (Bousmar and Zech 1999, Bousmar et al. 2004). Both approaches distinguish the mass exchange and turbulence exchange contributions in the interfacial momentum transfer.

The first 1D modelling considered in the following analysis is the classical Divided Channel Method (DCM), which is the reference case since it ignores both turbulent and mass transfers between subsections.

The Bousmar and Zech (1999) model, called Exchange Discharge Method (EDM) is the second modelling investigated. EDM is based on a theoretical modelling of the interfacial momentum transfer, tested for flows in slightly skewed compound channels and for a compound channel with narrowing floodplains. The interfacial shear on the subsection boundary is evaluated by using a mixing length model in the horizontal plane, and by expressing a turbulent exchange lateral discharge, noted $q^{t}$, and modeled by:

$$
q^{t}=0.16 \cdot h_{f p}\left(U_{m c}-U_{f p}\right)
$$

where $h_{f p}$ is the mean flow depth on the floodplain, and the value 0.16 is a coefficient that was calibrated from nine series of uniform flows in the FCF of HR Wallingford (Bousmar and Zech 1999). 
The mass exchange is represented by a lateral mass discharge $q^{m}=\left|d Q_{f p} / d x\right|$. EDM takes the momentum transfer due to this mass exchange into account. However, this model can be used considering the turbulent momentum transfer only: it will be designated in that case as EDM*.

The last modelling under consideration is the Debord formula (Nicollet and Uan 1979). It is an empirical method that was developed on the basis of large experimental data sets in a $60 \mathrm{~m}$ x $3 \mathrm{~m}$ straight compound-channel flume. The Debord formula gives an estimate of the conveyance on the whole cross-section, $K^{*}$, by modifying the one of the DCM as follows:

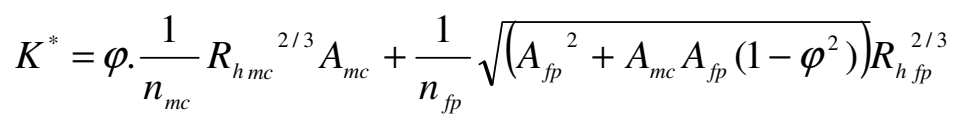

where $\varphi$ is a parameter that accounts for turbulent exchanges, modeled by:

$$
\begin{array}{ccl}
\varphi=\varphi_{o}=0.9\left(n_{m c} / n_{f p}\right)^{1 / 6} & & r=R_{h f p} / R_{h m c} \geq 0.3 \\
\left.\varphi=\frac{1}{2}\left\{1-\varphi_{o}\right] \cos (\pi r / 0.3)+\left[1+\varphi_{o}\right]\right\} & \text { if } \quad & r=R_{h f p} / R_{h m c} \leq 0.3
\end{array}
$$

In that way, it is close to more recent empirical formulae such as Ackers' $(1991,1992)$ or to previous expressions proceeding from the computation of an apparent shear stress acting at the interfacial boundary (Knight \& Demetriou 1983, Wormleaton \& Merett 1990). The Debord method has been extensively used for more than 20 years by French modelers. It accounts for turbulent transfers but not for mass exchanges in the momentum transfers.

\section{Influence of possible turbulent exchanges on discharge distribution modelling}

In order to evaluate the contribution of possible turbulent exchanges related to the velocity gradient between subsections, the subsection-averaged values of discharge and velocity were calculated at each measurement station of the reach, for equivalent uniform flows of same cross-section area, using the actual experimental water level, averaged on the whole width. Three different calculations were conducted: with the DCM (reference 
calculation), with the $\mathrm{EDM}^{*}$ and with Debord. Fig. 7 gives the resulting floodplain discharges, and Tab. 2 presents the relative errors between computed and experimental values. The floodplain discharge computed by the DCM deviates from the experiments towards downstream, with a maximum discrepancy of $-57 \%$ (resp. $-37 \%$ ) at the last station for $Q=$ 150 1/s (resp. 260 1/s). This indicates the significance of interfacial transfers (mass and/or turbulence) in the evaluation of the discharge distribution. Considering possible turbulent exchanges reduces the discrepancies, but the floodplain discharge is still noticeably underestimated downstream (-34\% for $Q=150 \mathrm{l} / \mathrm{s}$ and the Debord formula).

Fig. 9 presents the experimental mean velocities in the floodplain, the values calculated by the Debord formula, the DCM and EDM*. Experimental values computed with the actual subsection discharges but with an averaged value of the water level across the whole width $\left(Z_{\text {mean }}\right)$ instead of the actual subsection level $\left(Z_{s u b}\right)$ are also given, in order to evaluate the influence of the transverse water slope in the downstream part. Debord and $\mathrm{EDM}^{*}$ model experimental values between the first two stations $(0 \mathrm{~m}<x<2.5 \mathrm{~m})$ accurately. Notable differences between DCM values and experimental ones highlight the role of the interfacial turbulent exchange modelling. Not considering the mass exchange in the momentum transfer is not prejudicial in this upstream part of the reach. Between $x=3.5$ and $4.5 \mathrm{~m}$ the DCM values are noticeably erroneous, with a maximum error of $62 \%$ for $Q=150$ 1/s. Values of Debord and $\mathrm{EDM}^{*}$ are closer to experimental results, but an underestimation of the mean velocity of $39 \%$ at $x=4,5$ m clearly demonstrates that accounting only for possible turbulent transfer is not sufficient. Assuming a unique water level in a cross-section cannot explain this discrepancy, since it gives an error of $9 \%$ on the floodplain mean velocity only.

The increasing difference between DCM, and Debord and EDM* towards downstream, is in agreement with the literature (Ackers 1991): as the relative water depth $h_{r}$ is decreasing, the role of turbulence transfer for the equivalent uniform flow is increasing. 
However, near the reach end, the gradient of experimental velocity between the main channel and the floodplain is quite low for $Q=150 \mathrm{l} / \mathrm{s}$ and even nil for $Q=260 \mathrm{l} / \mathrm{s}$ (Fig. $4, U_{d^{-}}$ components). Measurements of the Reynolds stresses $\rho u^{\prime} v^{\prime}$ obtained with the NDV probe for the higher discharge confirm the low level of the associated turbulence. The increase of the floodplain velocity is in fact due to mass exchange, as 2D modeling will also prove hereafter. Accordingly, Debord and EDM* artificially add dissipation between both subsections, by means of turbulent exchanges due to a velocity gradient not physically observed in the downstream part of the reach. Adding such an artificial momentum transfer reduces prediction errors on both discharge distribution and subsection velocities.

\section{The total interfacial exchanges}

As mentioned above, some 1D models developed for slightly non-prismatic geometry also take into account momentum transfer due to the mass exchange. The complete EDM will be used as framework to evaluate this contribution. The momentum equation is written for the main channel as an energy balance by introducing the mass conservation (See- Appendix II.a):

$$
\frac{\partial}{\partial x}\left(Z_{m c}\right)+\frac{1}{g} U_{m c} \frac{\partial U_{m c}}{\partial x}+S_{f_{m c}}+S_{a_{m c}}=0 \quad \text { with } \quad S_{a m c}=\left(q^{t}+q^{m}\right) \frac{\left(U_{m c}-U_{f p}\right)}{g A_{m c}}
$$

This equation expresses the balance between the head slope (the first two terms), the bed friction slope, and an interfacial transfer term written as an additional loss. A similar equation is obtained for the floodplain:

$$
\frac{\partial}{\partial x}\left(Z_{f p}\right)+\frac{1}{g} U_{f p} \frac{\partial U_{f p}}{\partial x}+S_{f_{f p}}+S_{a f p}=0 \quad \text { with } \quad S_{a f p}=q^{t} \frac{\left(U_{f p}-U_{m c}\right)}{g A_{f p}}
$$

where no inflow $q^{m}$ due to mass transfers is considered as the water only leaves the converging floodplain. 
Fig. 10 gives values of the additional 1D-head losses gradients, $S a_{m c}$ and $S a_{f p}$, estimated from the experimental values of $U_{m c}, U_{f p}, h_{m c}$, and $h_{f p}$. No significant variation of these additional head losses slopes along the flow are observed: the increase of lateral mass discharge $q^{m}$ towards downstream is partially balanced by the decrease in the velocity gradient. The performance of the 1D model depends on these values of $S a_{m c}$ and $S a_{f p}$, which are supposed to account for $2 \mathrm{D}$ or $3 \mathrm{D}$ dissipation in the subsections. Accordingly, one resorted to $2 \mathrm{D}$ simulations so as to assess the relevance of these values. If the $2 \mathrm{D}$ program manages to model the main hydraulic parameters, a comparison of the $2 \mathrm{D}$ additional head losses gradients (averaged on each subsection) with $1 \mathrm{D}$ values of $S a_{m c}$ and $S a_{f p}$ would enable concluding.

\section{D COMPUTATIONS}

2D simulations were made by means of the numerical program MAC2D (Bousmar 2002). Mac2D solves the shallow water equations using a finite-difference method based on a Mac-Cormack scheme. The grid is made up of quadrilaterals of mean size $(5 \mathrm{~cm} \mathrm{x} 4.5 \mathrm{~cm})$.

The momentum equation in $x$-direction, at a lateral position $y$, can be written as an energy equation by introducing the mass conservation:

$$
\frac{d Z}{d x}+\frac{1}{g} U_{d} \frac{d U_{d}}{d x}+\frac{1}{g} V_{d} \frac{d U_{d}}{d y}+S_{f_{x}}-T_{x x}-T_{x y}=0
$$

where the terms $T_{x x}$ and $T_{x y}$ are related to depth-averaged Reynolds stresses $\tau_{x x}$ and $\tau_{x y}$

Regarding the turbulent model, a eddy viscosity proportional to shear velocity and water depth was used: $v^{t}=\lambda \cdot U^{*} \cdot h$. According to Rodi (1980), the value of the adimensional parameter $\lambda$ is in the range 0.1 to 0.2 for wide laboratory flumes. A constant $\lambda$ value of 0.1 was first used. 
Typical Mac 2D results are summarized on Fig. 11 for $Q=150$ 1/s. Mac2D quite accurately represents the hydraulic parameters distribution for both discharges. The water levels are modeled with maximum errors of $6 \%$ (of the mean flow depth on the floodplain), the components $U_{d}$, with an error of $14 \%$, and components $V_{d}$ with maximum errors of $15 \%$ for $Q=150 \mathrm{l} / \mathrm{s}$ and $35 \%$ for $Q=260 \mathrm{l} / \mathrm{s}$.

Main results regarding the momentum transfer are: (1) The term $T_{x x}$ is always negligible compared to the others terms in Eq. (7); and (2) Subsection-averaged value of $\mathrm{V}_{d} d U_{d} / d y$ is larger than $T_{x y}$ (up to a ratio of 10 for the lower discharge) in the converging reach. Besides, increasing the $\lambda$ value to 0.2 in the turbulent model does not affect the results.

It shows that turbulent exchanges are vanishing when mass transfers become severe. They confirm the results of Wilson et al. (2002) who demonstrated the weak role of a turbulent model in meandering compound channels.

\section{COMPARISON BETWEEN 2D AND 1D HEAD LOSSES GRADIENTS}

The comparison between (5), (6) and (7) indicates that the additional 1D head loss gradient in a subsection $\left(S a_{m c}\right.$ or $\left.S a_{f p}\right)$ corresponds to the subsection-averaged value of $\left(1 / g . V_{d} \partial U_{d} / \partial y-T_{x y}-T_{x x}\right)$, denoted as $S_{a 2 D}$.

Values of $S_{a 2 D}$ can be compared with $S a_{m c}$ or $S a_{f p}$ (Fig. 10). Both values are of the same magnitude order in the main channel, but not in the floodplain where their signs can be opposite. The additional head loss as modeled by EDM does not correctly account for 2D dissipation within the subsections. A further analysis of the $1 \mathrm{D}$ equations is necessary to understand this observation.

When developing (5) and (6), it has been assumed that the longitudinal velocity of water leaving the flood plain was equal to the flood plain mean velocity. However, the water 
volume that is transferred from the floodplain to the main channel is close to the interface, its actual velocity is thus not equal to the flood plain mean velocity (Fig. 12). Accounting for this difference in (5) and (6) gives :

$$
\begin{aligned}
& \frac{1}{g} U_{m c} \frac{\partial U_{m c}}{\partial x}+\frac{\partial Z_{m c}}{\partial x}+\frac{q^{t}\left(U_{\text {int. } m c}-U_{\text {int. } f p}\right)}{g A_{m c}}+\frac{q^{m}\left(U_{m c}-U_{\text {int. } f p}\right)}{g A_{m c}}+S f_{m c}=0 \\
& \frac{1}{g} U_{f p} \frac{\partial U_{f p}}{\partial x}+\frac{\partial Z_{f p}}{\partial x}+\frac{q^{t}\left(U_{\text {int. } f p}-U_{\text {int. } m c}\right)}{g A_{f p}}+\frac{q^{m}\left(U_{\text {int. } f p}-U_{f p}\right)}{g A_{f p}}+S f_{f p}=0
\end{aligned}
$$

where $U_{\text {int.mc }}$ and $U_{\text {int.fp }}$ are respectively the velocities near the interface in the main channel and in the floodplain. The development of (8) and (9) is given in Appendix II.b. These equations are written by distinguishing the contributions of turbulent and mass transfers. Additional head losses due to turbulent exchange are noted $S_{a m c}^{t}$ and $S_{a f p}^{t}$ in the main channel and the flood plain respectively, and write:

$$
S_{a_{m c}}^{t}=\frac{q^{t}\left(U_{\text {int. } m c}-U_{\text {int. } f p}\right)}{g A_{m c}} \text { and } \quad S_{a_{f p}}^{t}=\frac{q^{t}\left(U_{\text {int. } f p}-U_{\text {int. } m c}\right)}{g A_{f p}}
$$

Additional head losses due to mass transfers are noted, $S_{a_{m c}}^{m}$ and $S_{a_{f p}}^{m}$, and write:

$$
S_{a_{m c}}^{m}=\frac{q^{m}\left(U_{m c}-U_{\text {int. } f p}\right)}{g A_{m c}} \quad \text { and } \quad S_{a_{f p}}^{m}=\frac{q^{m}\left(U_{\text {int. } f p}-U_{f p}\right)}{g A_{f p}}
$$

The values of these head losses are presented on Tab. 3, at different coordinates $x$, for both discharges. They are calculated from experimental values of $h_{m c}, h_{f p}, U_{m c}, U_{f p}$, and $q^{m}$. For sake of simplicity, only one attempt is reported here, where the values of interfacial velocities $U_{\text {int.fp }}$ and $U_{\text {int.mc }}$ are the ones measured at $10 \mathrm{~cm}$ from side to side of the interface.

From $x=2.5 \mathrm{~m}, S_{a m c}^{t}$ is always negligible compared to $S_{a_{m c}}^{m}$, and in the flood plain, the term $S_{a_{f p}}^{m}$ is clearly not negligible since it becomes predominant compared to $S_{a_{f p}}^{t}$. 
Assuming that the interfacial velocity is equal to the floodplain mean value involves thus significant errors in the head losses evaluation in the flood plain when the transverse flow is marked. The problem lies in the use of only the subsection 1D velocities to account for 2D heterogeneity and lateral transfers within these subsections. Calculating of subsectionaveraged value of $1 / g V_{d} d U_{d} / d y$, at first magnitude order, highlights this phenomena. This value e.g. in the flood plain can be calculated from an eulerian point of view as follows:

$$
\frac{1}{Q_{f p}} \int_{A f p}\left(\frac{1}{g} V_{d} \frac{d U_{d}}{d y}\right) \cdot U_{d} \cdot h \cdot d y=\frac{1}{Q_{f p}} \int_{A f p}\left(\frac{1}{g} V_{d} \cdot h \cdot \frac{d\left(U_{d}{ }^{2} / 2\right)}{d y}\right) d y \approx \frac{1}{2 g Q_{f p}} V_{f p} h_{f p}\left(U_{\text {int. } f p}{ }^{2}-U_{f p . r i g h t}{ }^{2}\right)
$$

where $V_{f p}$ and $h_{f p}$ are the mean values of the $V_{\mathrm{d}}$-component and the flow depth on the floodplain; and $U_{f p . r i g h t}$ is the longitudinal velocity value close to the right side of the floodplain out of the boundary layer. $V_{d}$ is supposed to be constant on the subsection and equal to $V_{f p}$ (Fig. 4.), and $h$ equal to $h_{f p}$ (Fig. 3). Considering at first order that $U_{f p}=\left(U_{\text {int.fp }}+U_{f p . r i g h t}\right) / 2$, it writes:

$$
\frac{1}{Q_{f p}} \int_{A f p}\left(\frac{1}{g} V_{d} \frac{d U_{d}}{d y}\right) \cdot U_{d} . h . d y \approx \frac{1}{g Q_{f p}} U_{f p} V_{f p} h_{f p}\left(U_{\text {int. } f p}-U_{f p . r i g h t}\right)=\frac{1}{g A_{f p}} q^{m}\left(U_{\text {int } . f p}-U_{f p . r i g h t}\right)
$$

This magnitude order relation is verified experimentally for both discharges. Moreover, the value of $\frac{q^{m}}{g A_{f p}}\left(U_{\text {int.fp }}-U_{f p . r i g h t}\right)$ is larger but of the same magnitude order as the mass transfer contribution $S_{a f p}^{m}$, previously defined with $U_{f p}$ instead of $U_{f p . r i g h t}$. Not taking into account the $S_{a f p}^{m}$ is equivalent to assume the subsection mean value of $1 / g V_{d} d U_{d} / d y$ equal to zero. This is obviously erroneous in this abrupt flood plain. As a result, interfacial exchange terms of 1D models developed for slightly varying floodplain become irrelevant when the subsectionaveraged term of $1 / g V_{d} d U_{d} / d y$ increases. 
Considering interfacial velocities leads to new values of $S_{a_{m c}}=S_{a m c}^{t}+S_{a_{m c}}^{m}$ and of $S_{a_{f p}}=$ $S_{a_{f p}}^{t}+S_{a_{f p}}^{m}$ that are reported on Fig. 10. Their sign and their magnitude order are now similar to the ones of $2 \mathrm{D}$ additional head losses. Thus, one way to limit errors of $1 \mathrm{D}$ approaches would be to find a suitable way to forecast interfacial velocities in both subsections.

Eventually, the comparison between (5), (6) and (7) assumes that the 1D bed friction slope $S_{f}$, and the 2D one, $S_{f x}$, are equal. $S_{f}$ is computed using experimental 1D values, and $S_{f x}$ is given by Mac2D. Fig. 13 does not show significant discrepancy between these friction slopes, although the evaluation of $S_{f x}$ partly encompasses the value of the $v$-component of velocity.

\section{D COMPUTATIONS WITH NUMERICAL PROGRAMS}

Several possible weaknesses of 1D approaches in the abrupt contraction case have already been identified: (1) the modelling of interfacial mass transfer and the associated momentum; and (2) the assumption of a unique water level across the section in the last part of the studied reach. Additional errors can also arise from the $1 \mathrm{D}$ numerical programs, due e.g. to the choice of the equations, or to the setting of the boundary conditions. Three 1D programs were tested for this configuration: (1) Hec-RAS, from the USACE; (2) Talweg-Fluvia, developed by the Cemagref, Lyon, France; and (3) Axeriv, developed by the Université Catholique de Louvain, Louvain-la-Neuve, Belgium. All these programs predict water profiles, discharge distribution between subsections and subsection-averaged velocities.

\section{Solved equations}

Talweg-Fluvia (TF) accounts for the momentum transfer in compound channels through the Debord formula. It solves the 1D-momentum equation on the whole cross-section: 


$$
\frac{\partial Z}{\partial x}+\frac{1}{A} \frac{\partial}{\partial x}\left(\beta \frac{Q_{t o t}^{2}}{g A_{t o t}}\right)=-S_{f}
$$

where $Z$ is the free-surface level, $A_{\text {tot }}$ is the whole cross-section area, $\beta$ is the Boussinesq coefficient, and $S_{f}$ is the bed friction slope on the whole section. This latter is estimated using the assumption that the bed friction slope in a specific reach is the same as the one obtained for a uniform flow having the same hydraulic radius and averaged velocity (French 1985):

$$
S_{f}=Q_{t o t}^{2} / K^{* 2}
$$

where $K^{*}=$ the conveyance on the whole cross-section. The latter is influenced by the interaction between the main channel and the floodplain, taken into account in the Debord formula (3) by an empirical coupling coefficient (Nicollet and Uan 1979). The dissipation due to mass transfer linked to geometrical changes is not accounted for. Furthermore, no head slopes equality between the subsections is assumed explicitly, considering only the total conveyance of the equivalent uniform flow of the same cross-sectional area.

Axeriv models the momentum transfer with the EDM. It solves the Bernoulli equation on the whole cross-section:

$$
S_{H}=-\frac{\partial}{\partial x}\left(z+\alpha \frac{Q_{\text {total }}^{2}}{2 g A_{\text {total }}^{2}}\right)=S_{f}+S_{a}
$$

where $S_{H}$ is the total head slope; $\alpha$ is the Coriolis coefficient; $S_{f}$ is the bed friction slope computed by Manning's formula using DCM approach $\left(S_{f}=Q^{2} /\left(K_{m c}+K_{f p}\right)^{2}\right)$; and $S_{a}$ is the total additional loss defined by the EDM. It is estimated as a weighted value of the subsection $S a_{m c}$ and $S a_{f p}$; and the latter are computed by assuming locally the equality of subsection head slopes. Two different computations were carried out with Axeriv: (1) neglecting the dissipation due to lateral mass transfer $\left(\mathrm{EDM}^{*}\right)$; and (2) with the complete EDM. 
Hec-Ras solves the Bernoulli equation on the whole cross-section. It uses the DCM and accounts for contraction losses by an empirical equation. The head loss gradient is :

$$
S_{H}=-\frac{\partial}{\partial x}\left(z+\alpha \frac{Q_{\text {total }}^{2}}{2 g A_{\text {total }}^{2}}\right)=S_{f}+C\left|\frac{\partial}{\partial x}\left(\frac{\alpha U^{2}}{2 g}\right)\right|
$$

where $C$ is the contraction loss coefficient. A value of 0.1 was used according to the reference manual (Brunner 2001), as the transition is gradual (mean angle $22^{\circ}$ ) and the flow is subcritical on the whole cross-section.

In Hec-Ras, contraction losses were built to adjust the water profile, hence, they do not deal with discharge distribution. Further more, they do not depend of subsection discharges $Q_{i}$ since the kinetic energy coefficient only depends on the averaged water level $Z$ and subsection conveyances, and $U=U\left(Z, Q_{\text {total }}\right)$.

As Talweg-Fluvia, Hec-Ras does not explicitly assume head slopes equality between subsections.

\section{Water profile computations}

Fig. 14 shows the measured and computed water profiles . Two distinct experimental values correspond to main channel and floodplain averaged water levels $\left(Z_{m c}\right.$ and $\left.Z_{f p}\right)$. The downstream boundary condition used for the computation is the experimental water level, averaged across the whole channel width, $Z_{\text {mean }}$.

Talweg-Fluvia seems to provide more accurate water profile computation than Axeriv, whatever the interfacial exchange modeling, EDM* or EDM, and than Hec-Ras. At station $x$ $=0 \mathrm{~m}$, Talweg-Fluvia error corresponds to $2.6 \%$ (resp. $5.2 \%$ ) of the floodplain flow depth $h_{f p}$ for $Q=260 \mathrm{l} / \mathrm{s}($ resp. $150 \mathrm{l} / \mathrm{s}$ ), while EDM error is $10 \%$ (resp. $20 \%$ ) and DCM error is 6\% (resp. 9\%). 
EDM* and Talweg-Fluvia give different profiles though both models account for turbulent transfer only. The difference between both computed flow depths for $Q=260 \mathrm{l} / \mathrm{s}$ $($ resp. $150 \mathrm{l} / \mathrm{s})$ is $5.7 \%$ of $h_{f p}($ resp. $7.4 \%)$ at $x=0 \mathrm{~m}$.

Part of these discrepancies can be explained by the use of a Coriolis coefficient $\alpha$ in Axeriv (16) instead of a Boussinesq coefficient $\beta$ in Talweg-Fluvia (14). As $\alpha$ is a cubic function of the subsection velocities, its value and the one of its derivative $d \alpha / d x$ are more sensitive to errors on the computation of these velocities. This is particularly noticeable close to the downstream boundary condition, where the computation begins. Errors on the velocity prediction were indeed registered in this area as shown below. So, for $Q=1501 / \mathrm{s}$, the experimental value of coefficient $\beta$ varies in the range $[1.02 ; 1.08]$ and $\alpha$ in the range $[1.03$; 1.25] while $\beta$ values calculated by Talweg-Fluvia varie in the range [1.04; 1.08$]$ but $\alpha$ values calculated by EDM in the range $[1.06 ; 1.07]$ or DCM ones, in the range $[1.16 ; 1.36]$.

Conversely, the bed friction slope on the whole section $S_{f}$ is little sensitive (TalwegFluvia) or independent (Hec-Ras, Axeriv) of subsection velocities values, given an actual water level. Using only $\beta$ and $S_{f}$, the 1D momentum equation (14) is thus less dependent on the discharge distribution, than the Bernoulli equation with its $\alpha$ (Axeriv, Hec-Ras) and $S a$ (Axeriv).

Comparing $E D M$ and $E D M^{*}$ results with DCM ones indicates that turbulent transfers would have far less effect on water levels evolution than mass transfers within Axeriv. This is especially the case for the higher discharge where the computed turbulent exchange $q^{t}$ is negligible compared to $q^{m}$, (see eqs. 5 and 6). Eventually, $E D M^{*}$ is more effective than EDM for both discharges. This has no physical meaning considering the mass transfer domination in this configuration. A further analysis of subsection velocities is necessary to understand this contradiction. 


\section{Subsection-averaged velocities}

Computed and measured floodplain velocities are given on Fig. 15. None of the computations reproduces correctly the evolution of velocity along the whole reach. Similar observations are obtained for the main channel. Some results confirm the observations made previously on the velocity distribution for equivalent uniform flows (Fig. 9): (1) DCM values are more and more erroneous towards downstream, underlining the role of interfacial transfers modeling; (2) DCM corrections proposed by Debord (Talweg-Fluvia) and EDM* (Axeriv) are sufficient to account for velocity gradients between subsections, from $x=0$ to $2.5 \mathrm{~m}$, where mass transfers are moderate; (3) these corrections are no more satisfactory in the second part of the reach, where the mass transfers increase, with a velocity underestimation up to $58 \%$ for Talweg-Fluvia at the last station.

Axeriv results obtained with the complete EDM, considering both turbulent and mass transfers, require a more detailed analysis. At the station $x=4.5 \mathrm{~m}$ where the computation starts, the velocity gradients computed by EDM and EDM* are equal, since the mass transfer effect on the momentum is not yet taken into account. It has been shown that this gradient is larger than the actual experimental value (Fig. 9). In the first computation step towards upstream, the dissipation modeled in (5) and (6) by $S a_{m c}$ and $S a_{f p}$ is therefore overestimated. This results in the too high water levels observed on Fig. 14. Furthermore, neglecting the term $S_{a f p}^{m}$ related to interfacial velocity $U_{\text {int.fp }}$ is already prejudicial in this step (Tab. 3). For further computation steps towards upstream, the two sources of error on the interfacial transfers keep on superimposing: (1) the artificial velocity gradient stemming from downstream; and (2) the confusion between velocities close to the interface and the subsection ones. This explains the different evolution of the experimental and the EDM computed subsection velocities. 


\section{Discussion on 1D numerical modeling.}

The water profiles are computed by the three programs, Hec-Ras, Talweg-Fluvia and Axeriv, on the whole cross-section. The 1D momentum equation (14) is less sensitive to discharge distribution prediction than Bernoulli equation (16). As a result, the computed water profile by Talweg-Fluvia is surprisingly close to the experimental ones when considering the poor results obtained for the subsection velocities in the downstream part of the reach.

Regarding Hec-Ras results, contraction losses can be used so as to adjust the water profile, but not the discharge distribution. Indeed, between $\mathrm{x}=2 \mathrm{~m}$ and $\mathrm{x}=4.5 \mathrm{~m}$, the water surface profile is modeled with a maximum error of $+5 \%$ of the mean water depth in the floodplain, $h_{f p}$, while the error on the floodplain discharge reaches $-57 \%$ (for $\mathrm{Q}=150 \mathrm{l} / \mathrm{s}$ ) with a contraction coefficient $C$ equal to 0.1 . Increasing this coefficient worsens the situation in term of water surface profile while reducing this factor enables to adjust the water profile in the converging reach. However, in both cases the $\mathrm{C}$ factor value has little effect on the discharge distribution especially close to the downstream boundary condition where the water level is fixed.

Considering Axeriv computations, errors on the calculation of additional head loss gradients $S a, S a_{m c}$ and $S a_{f p}$ involve significant errors on the water profiles computation, notably close to $x=4.5 \mathrm{~m}$ where the computation starts. The subsection mean velocities obtained with the EDM highlighted some further weaknesses: as mass transfers originate physically from upstream (Bousmar et al. 2005, Proust 2005), it is difficult to start the computation from downstream with a relevant discharge distribution. Furthermore, comparison with $2 \mathrm{D}$ modeling demonstrates that the use of interfacial velocities in the computation of mass exchanges between subsections is necessary to account for transverse flows ( $2 \mathrm{D}$ effects) when they become severe. This raises the problem of the determination of different relevant interfacial velocities from a subsection-boundary side to an other. Besides, 
the subsection head slopes equality assumed by the EDM could be an other source of discrepancies between computed and experimental values.

\section{CONCLUSIONS}

The flow in a compound channel transition reach presenting an abrupt floodplain contraction (mean angle of $22^{\circ}$ ) has been investigated experimentally. With such a strong contraction, a noticeable mass transfer occurs from the floodplain towards the main channel. Specific phenomena associated to this severe mass transfer are highlighted: (1) a transverse water surface gradient appears in the narrowest cross-section; and (2) the head evolution is different in the main channel and in the floodplain. Besides, 2D computations are used to evaluate the $2 \mathrm{D}$ head loss gradients and the relative weight of the different dissipation sources. They show that turbulent exchanges are vanishing when mass transfer becomes severe, as observed by Wilson et al. (2002) in meandering compound channels. Their accuracy is satisfactory since the water surface profile and the longitudinal component $U_{d}$ are modeled with a maximum error of $6 \%$ and $12 \%$, respectively.

Then, the relevance of three 1D numerical models developed for prismatic or slightly non-prismatic compound channel has been analyzed. Their effectiveness is directly related to the accuracy of the interfacial transfer modeling - notably the mass exchanges and the associated momentum transfer - and can be worsened by assumptions such as a same head loss gradient in the two subsections.

1D models such as Talweg-Fluvia or Axeriv with EDM* only account for turbulent exchange between subsections. Assuming the discharge distribution is the one of the equivalent uniform flow of same cross-section area all along the flow, they minimize error prediction on subsection discharges by adding turbulent dissipation, which has no physical 
sense in the converging part of the reach. In any case, a velocity underestimation up to $35 \%$ still remains for Talweg-Fluvia at the last station. Considering Hec-Ras results, errors on the mean flow depth and mean velocity in the floodplain are $10 \%$ and $57 \%$, respectively. The actual discharge distribution cannot be modeled by calibrating the contraction coefficient in Bernoulli equation. Axeriv with the complete EDM was validated for overbank flows in symmetrically narrowing floodplains (Bousmar et al. 2004) for which, converging angles were $3.8^{\circ}$ or $11.3^{\circ}$. In this abrupt floodplain, the additional 1D head loss gradient calculated by the EDM is less relevant, leading to error of $20 \%$ and $37 \%$ on mean flow depth and mean velocity in the floodplain, respectively. The comparison of 2D and 1D head loss gradients enables quantifying the role of the lateral velocity components and lateral gradient of longitudinal velocities, which is significant in the studied configuration. $2 \mathrm{D}$ effects could be integrated in the EDM by considering and computing interfacial velocities.

For the three models, assuming that the water level is equal in both beds of the same cross-section participates to the discrepancy, with maximum error of $9 \%$ on the floodplain mean velocity. Accordingly, erroneous results on the discharge distribution arise because of: (1) this assumption of a unique water level in the narrowest cross-section; (2) incorrect estimation of momentum exchange due to lateral mass transfers; (3) the assumption of equality between head loss gradients in the two beds. Further more, a fourth source of discrepancy was identified: the downstream boundary conditions that are imposed by current 1D models. Indeed, the 1D codes usually assume that the downstream discharge distribution is the same as the one of the equivalent uniform flow. This assumption is not realistic and influences the computation of lateral mass discharge in the EDM, from downstream towards upstream. In transition reaches, a relevant calculation should consider the actual subsection discharges in addition to the water level. 
Eventually, capacities and limitations of the three different 1D codes were described. Though they are effective in straight or slightly varied compound channel geometries (converging angle up to $11^{\circ}$ for the EDM), their results appear not to be relevant for a mean angle of $22^{\circ}$. Accordingly, when simultaneous prediction of both water levels and mean velocity in the flood plain is needed, e.g. for the evaluation of vulnerability in urbanized flood plains or sediment transport in natural floodplains and for the science of habitat hydraulics, 1D models should not be used if mass transfer become severe.

However, as only one geometric configuration with two flow rates was tested, further work should be devoted to the understanding of severe mass transfers in non-prismatic compound channels.

\section{ACKNOWLEDGMENTS}

Experiments in CNR flume were funded by PNRH99-04 research programme. D.Bousmar, N.Rivière and S.Proust travel costs were supported by the Tournesol programme grant 02947VM funded by EGIDE, France and CGRI, Communauté française de Belgique. 


\section{APPENDIX I. REFERENCES}

Abril, J. B., and Knight, D. W. (2004). "Stage-discharge prediction for rivers in flood applying a depth-averaged model." Journal of Hydraulic Research, 42(6), 616-629.

Ackers, P. (1991). "Hydraulic design of straight compound channels.” Rep. No. SR281, HR Wallingford.

Ackers, P. (1992). "Hydraulic design of two-stage channels.” Proc., I.C.E., Water, Maritime and Energy, Thomas Telford, London, 96(4), 247-257.

Bousmar, D. and Zech, Y. (1999). "Momentum transfer for practical flow computation." Journal of Hydraulic Engineering, ASCE, 125(7), 696-706.

Bousmar, D. (2002). «Flow modelling in compound channels, momentum transfer between main channel and prismatic or non-prismatic flood plains. » PhD-Thesis, Université Catholique de Louvain, Louvain-la-Neuve, Belgium.

Bousmar, D., Wilkin, N., Jacquemart, J.-H. and Zech, Y. (2004), "Overbank flow in symmetrically narrowing floodplains." Journal of Hydraulic Engineering, ASCE, 130 (4), 305-312.

Bousmar, D., Rivière, N., Proust, S., Paquier, A., Morel, R., and Zech, Y. (2005). "Upstream discharge distribution in compound-channel flumes." Journal of Hydraulic Engineering, ASCE, 131(5), 408-412.

Brunner, G. W. (2001). "Hec-Ras, River Analysis system - Hydraulic Reference Manual." USACE, Inst. for Water Resources, Hydrologic Engineering Center, Davis CA, CPD69.

Elliot, S. C. A. and Sellin, R. H. J. (1990). "SERC Flood channel facility : skewed flow experiments." Journal of Hydraulic Research, Delft, The Netherlands,_28(2), 197-214.

French, R. H. (1985). “Open Channel Hydraulics.” McGraw-Hill, New -York. 
Hunt, H., Brunner, G.W., and Larock, B.E., (1999). "Flow transitions in bridge backwater analysis.” Journal of Hydraulic Engineering, ASCE, 125 (9), 981-983.

Jasem, H. K. (1990). "Flow in two-stage channels with the main channel skewed to the flood plain direction.” $\mathrm{PhD}$ Thesis, University of Glasgow, U.K.

Knight, D. W. and Demetriou, J. D. (1983). "Floodplain and main channel flow interaction." Journal of Hydraulic Engineering, ASCE, 109(8), 1073-1092.

Knight, D. W. and Rhodes, D. G. (1994). "Velocity and boundary shear in a wide compound duct." Journal of Hydraulic Research, Delft, The Netherlands, 32(5).

Lancastre, A., (1999). « Hydraulique générale. », Eyrolles, Paris.

Martin-Vide, J. P., Lopez-Querol, S., and Martin-Moretta, P. (2004). "Improving 1-D modelling of open channel flow in compound channels." Proc. of the 2nd int. conf. on fluvial hydraulics, River flow 2004, 23-25 june,, Napoly, Italy, Greco, Carravetta \& Della Morte (eds.), 415-422.

Nicollet, G. and Uan, M. (1979). "Ecoulements permanents à surface libre en lit composés." La Houille Blanche, Grenoble, France, (1), 21-30.

Proust, S., Rivière, N., Bousmar, D., Paquier, A. and Morel, R. (2002). "Velocity measurements in a concrete experimental channel representing a flood plain." Proc. Hydr. Meas. and Exp. Meth., Eastes Park, Colorado, ASCE, CD-Rom.

Proust, S. (2005). "Non-uniform flows in compound channels: effect of flow-width variations in the floodplain.” PhD-Thesis, n 2005-ISAL-0083, INSA Lyon, Lyon, France.

Rivière, N., Proust, S., Bousmar, D., Paquier, A., Morel, R., and Zech, Y. (2002). "Relevance of 1D flow modelling for compound channels with a converging floodplain." River Flow 2002, Proceedings of the International Conference on Fluvail Hydraulics, 4-6 Septembre 2002, Louvain-la-Neuve, Belgium, 1, 187-195. 
Rodi, W. (1980). Turbulence models and their application in hydraulics : a state of the art review, IAHR book publication, Delft.

Sellin, R. H. J., Ervine, D. A., and Willetts, B.B. (1993). "Behaviour of meandering two-stage channels.” Proc. Institution of Civil Engineers, Water, Maritime and Energy, 101, 99111.

Shiono, K. and Muto, Y. (1998). "Complex flow mechanisms in compound meandering channels with overbank flow." Journal of Fluid Mechanics, Cambridge, England, 376, 221-226.

Shiono, K., and Knight, D. W. (1991). "Turbulent open channel flows with variable depth across the channel." Journal of Fluid Mechanics, Cambridge, England, 222, 617-646.

Sturm, T. W., Janjua, N.S. (1994). "Clear-water scour around abutments in floodplains“. Journal of Hydraulic Engineering, 120(8), 956-972.

Wilson, C., Bates, P. D., and Hervouet, J. M. (2002). "Comparison of turbulence models for stage-discharge rating curve prediction in reach-scale compound channel flows using two-dimensional finite element methods." Journal of Hydrology, 257(1-4), 42-58.

Wormleaton, P. R. and Merrett, D. J. (1990). "An improved method of the calculation for steady uniform flow in prismatic main channel/flood plain sections." Journal of Hydraulic Research, Delft, The Netherlands, 28(2), 157-174.

Yen, B. C. (1984). « Hydraulics of flood plains : methodology for backwater computation.” Report Nr. 84/5 (HWV 053), Institut für wasserbau , Universität Stuttgart, Stuttgart, Germany.

Yen, B.C., Camacho, R., Kohane, R. and Westrich, B. (1985). "Significance of flood plains in backwater computation.” Proc. 21st Congress of IAHR, Melbourne, Australia, vol(3), pp. $439-445$. 
Yen, B. C. (2002). "Open Channel Flow Resistance." Journal of Hydraulic Engineering, ASCE, 128(1), 20-39. 


\section{APPENDIX II. INFLUENCE OF INTERFACIAL VELOCITIES IN THE MOMENTUM}

a) Equations of the Exchange Discharge Model (EDM)

These equations are described in (Bousmar and Zech, 1999). Using the principle of conservation of momentum into a control volume, the momentum equation in the $x$-direction for a unit length gives:

$\frac{\partial}{\partial t}(\rho A U)=-\frac{\partial}{\partial x}\left(\rho A U^{2}\right)+\rho q_{\text {in }} U_{a d j}-\rho q_{o u t} U+\rho g A\left(S_{o}-S_{f}\right)-\rho g A \frac{\partial H}{\partial x}$

where $q_{\text {in }}$ and $q_{\text {out }}$ are respectively the inflow and outflow lateral discharge. It is assumed that: (1) the longitudinal velocity of water leaving the subsection is equal to the subsection mean velocity into the control volume, $U$; (2) the longitudinal velocity of water entering the subsection is equal to the mean velocity into adjacent subsection, noted $U_{\text {adj. }}$

The continuity equation gives:

$\frac{\partial A}{\partial t}+\frac{\partial Q}{\partial x}=q_{\text {in }}-q_{\text {out }}$

Developing (18) leads to:

$A \frac{\partial U}{\partial t}+U \frac{\partial A}{\partial t}+A U \frac{\partial U}{\partial x}+U \frac{\partial A U}{\partial x}+g A \frac{\partial H}{\partial x}-g A S_{o}=q_{\text {in }} U_{\text {adj. }}-q_{\text {out }} U-g A S_{f}$

Subtracting (19) multiplied by $U$ to (20), it comes:

$A \frac{\partial U}{\partial t}+A U \frac{\partial U}{\partial x}+g A \frac{\partial z}{\partial x}=q_{i n}\left(U_{a d j .}-U\right)-g A S_{f} \quad$ with $\frac{\partial H}{\partial x}-S_{o}=\frac{\partial z}{\partial x}$

equivalent to:

$A \frac{\partial U}{\partial t}+g A \frac{\partial}{\partial x}\left(z+\frac{U^{2}}{2 g}\right)=q_{i n}\left(U_{a d j .}-U\right)-g A S_{f}$ 


\section{b) New EDM equations considering interfacial velocities}

These equations are derived in Proust (2005). As the water volume that is transferred through the interface is close to this latter, its actual velocity is not equal to the mean subsection velocity: (1) the longitudinal velocity of water leaving the subsection is equal to velocity close to the interface into the control volume, noted $U_{\text {int }}$; (2) the longitudinal velocity of water entering the subsection is equal to velocity close to the interface into the adjacent subsection, noted $U_{\text {int } \cdot \text { adj }}$

Accounting for this difference, (18) becomes for steady flows:

$$
0=-\frac{\partial}{\partial x}\left(\rho A U^{2}\right)+\rho q_{i n} U_{\text {int.adj. }}-\rho q_{\text {out }} U_{\text {int. }}+\rho g A\left(S_{o}-S_{f}\right)-\rho g A \frac{\partial H}{\partial x}
$$

Mass conservation for steady flows becomes:

$$
\frac{\partial A U}{\partial x}=q_{i n}-q_{\text {out }}
$$

Subtracting (24) multiplied by $\rho U$ to (23), it comes:

$$
A U \frac{\partial U}{\partial x}+g A \frac{\partial Z}{\partial x}=q_{i n}\left(U_{\text {int. } a d j}-U\right)+q_{\text {out }}\left(U-U_{\text {int }}\right)-g A S_{f}
$$

equivalent to:

$$
-\frac{\partial}{\partial x}\left(Z+\frac{U^{2}}{2 g}\right)=\frac{q_{\text {in }}}{g A}\left(U-U_{\text {int.adj. }}\right)+\frac{q_{\text {out }}}{g A}\left(U_{\text {int }}-U\right)+S_{f}
$$

In the studied configuration, the water leaves the floodplain, and (26) becomes:

in the main channel, where $q_{\text {in }}=q^{m}+q^{t}, q_{\text {out }}=q^{t}, U_{\text {int }}=U_{\text {int.mc }}$, and $U_{\text {int.adj. }}=U_{\text {int.fp }}$

$$
-\frac{\partial}{\partial x}\left(Z_{m c}+\frac{U_{m c}^{2}}{2 g}\right)=\frac{\left(q^{t}+q^{m}\right)}{g A}\left(U_{m c}-U_{\text {int }{ }_{f p} .}\right)+\frac{q^{t}}{g A}\left(U_{\text {int. } m c}-U_{m c}\right)+S_{f}
$$

in the floodplain, where $q_{\text {in }}=q^{t}, q_{\text {out }}=q^{m}+q^{t}, U_{\text {int }}=U_{\text {int.fp }}$, and $U_{\text {int.adj. }}=U_{\text {int.mc }}$ :

$$
-\frac{\partial}{\partial x}\left(Z_{f p}+\frac{U_{f p}^{2}}{2 g}\right)=\frac{q^{t}}{g A}\left(U_{f p}-U_{\mathrm{int} \cdot m c}\right)+\frac{\left(q^{t}+q^{m}\right)}{g A}\left(U_{\mathrm{int} \cdot f p}-U_{f p}\right)+S_{f}
$$




\section{APPENDIX III. NOTATIONS}

\section{The following symbols are used in this paper :}

$A=$ section area;

$B=$ subsection width;

$d x=$ longitudinal unit length along reach abscissa $x$;

$d y=$ transverse unit length along lateral $y$-direction;

$d z=$ transverse unit length along vertical $z$-direction;

$g=9.81 \mathrm{~m} / \mathrm{s}^{2}$, gravity constant;

$H=$ head ;

$h=$ water level depth above channel bottom;

$h_{r}=$ relative water depth;

$K=$ section conveyance;

$K^{*}=$ section conveyance corrected for interaction;

$n=$ Manning roughness coefficient;

$Q=$ discharge

$q=$ lateral exchange discharge per unit length;

$q_{\text {in }}=$ lateral inflow per unit length;

$q^{m}=$ lateral discharge due to mass transfer ;

$q_{\text {out }}=$ lateral outflow per unit length;

$q^{t}=$ lateral discharge due to turbulent exchange ;

$R_{h}=$ section hydraulic radius ;

$S_{a}=$ additional head loss due to main channel/floodplain interaction ;

$S_{a}{ }^{m}=$ additional head loss due to mass transfer;

$S_{a}{ }^{t}=$ additional head loss due to turbulent exchange;

$S_{f}=$ friction slope ;

$S_{H}=$ head slope;

$S_{o}=$ bed slope ;

$u=$ local longitudinal velocity;

$U=$ section mean longitudinal velocity;

$U_{d}=$ depth-averaged longitudinal velocity;

$U_{\text {int }}=$ Longitudinal velocity close to the interface in a subsection;

$U_{\text {int.adj. }}=$ Longitudinal velocity close to the interface in the adjacent subsection;

$v=$ local transverse velocity in the lateral $y$-direction;

$V=$ section mean transverse velocity;

$V_{d}=$ depth-averaged transverse velocity;

$w=$ local transverse velocity in the vertical $z$-direction;

$Z=$ water level above reference datum;

$Z_{b}=$ bed level above reference datum;

$\rho=$ density of water;

$\alpha=$ Coriolis coefficient;

$\beta=$ Boussinesq coefficient;

\section{Subscripts}

mean = concerning the whole cross-section

sub $=$ concerning subsection

$f p=$ concerning floodplain

$m c=$ concerning main channel 


\section{List of figure captions}

Fig. 1. Compound channel flume of the Compagnie Nationale du Rhône (CNR)

Fig. 2. Experimental set-up scheme

Fig. 3. Lateral profiles of water levels $-Q=2601 / \mathrm{s}$

Fig. 4. Lateral distributions of depth-averaged velocities: (a) longitudinal component $\mathrm{U}_{\mathrm{d}}$; (b) transverse component, $\mathrm{V}_{\mathrm{d}}$.

Fig. 5. Velocities field in the vertical plane $x=3.5 \mathrm{~m}-\mathrm{Q}=260 \mathrm{l} / \mathrm{s}$

Fig. 6. Velocities field measured near the bottom $\left(0.2 \mathrm{~h}_{\mathrm{mc}}\right)$ and the surface $-\mathrm{Q}=260 \mathrm{l} / \mathrm{s}$.

Fig. 7. Floodplain discharge as percentage of total discharge - calculations against data.

Fig. 8. Head profiles in the whole cross-section and in the subsections

Fig. 9. Evolution of the mean velocity in the floodplain

Fig. 10. Experimental 1D additional head loss gradients $S_{a}$ and 2D computed ones $S_{a .2 D}$ in both subsections.

Fig. 11. Distribution of velocity components, $U_{d}$, and $V_{d}$, computed by MAC 2D for $Q=150$ $l / s$.

Fig. 12. Schematic lateral profile of longitudinal depth-averaged velocity $U_{d}$

Fig. 13. Experimental bed friction slope $S_{f}(1 \mathrm{D})$ and computed one $S f_{x}(2 \mathrm{D})$, in both subsections

Fig. 14. Longitudinal water surface profiles - Calculation against experimental data.

Fig. 15. Floodplain velocity profiles - Calculation against experimental data. 
Table 1. Upstream and downstream flow conditions - Relative water depth $h_{r}$ and ratio $Q_{f p} / Q$

\begin{tabular}{|c|c|c|c|c|}
\hline \multirow{2}{*}{$\begin{array}{c}\text { Abscissa } X \\
(\mathrm{~m})\end{array}$} & \multicolumn{2}{|c|}{ Discharge, $Q=1501 / \mathrm{s}$} & \multicolumn{2}{|c|}{ Discharge, $Q=2601 / \mathrm{s}$} \\
\hline & $\begin{array}{c}\text { Relative water } \\
\text { depth. } h_{r} \\
{[-]}\end{array}$ & $\begin{array}{c}\text { Discharge ratio } \\
Q_{f p} / Q(\mathrm{x} 100)[\%]\end{array}$ & $\begin{array}{c}\text { Relative water } \\
\text { depth. } h_{r} \\
{[-]}\end{array}$ & $\begin{array}{c}\text { Discharge ratio } \\
Q_{f p} / Q(\mathrm{x} 100) \\
{[\%]}\end{array}$ \\
\hline 0 & 0.23 & 26.0 & 0.42 & 51.7 \\
\hline 4.5 & 0.14 & 9.5 & 0.33 & 24.2 \\
\hline
\end{tabular}


Table 2. Percentage of relative error on the floodplain discharge calculation $-\left(\mathrm{Q}_{\mathrm{fp}}\right.$.calc. $-\mathrm{Q}_{\mathrm{fp}}$.exp. $) / \mathrm{Q}_{\mathrm{fp}} . \exp .(\mathrm{x} 100)$

\begin{tabular}{lcccccc}
\hline $\mathrm{X}(\mathrm{m})$ & \multicolumn{5}{c}{$\mathrm{Q}=150 \mathrm{l} / \mathrm{s}$} & $\mathrm{Q}=260 \mathrm{l} / \mathrm{s}$ \\
\hline & \multicolumn{7}{c}{ Relative error $(\%)$} \\
\cline { 2 - 7 } 0 & DCM & Debord & EDM $^{*}$ & DCM & Debord & EDM $^{*}$ \\
\cline { 2 - 7 } & -10.9 & 7.9 & 10.9 & -14.9 & -5.0 & -5.4 \\
2.5 & -16.6 & 2.0 & 4.9 & -10.5 & 0.3 & 0.4 \\
3.5 & -36.9 & -9.1 & -5.0 & -25.2 & -7.0 & -8.1 \\
4.5 & -57.4 & -34.4 & -25.8 & -36.7 & -14.4 & -16.1 \\
\hline
\end{tabular}


Table 3. Additional head losses due to mass transfer ( $S_{a_{f p}}^{m}$ and $S_{a_{m c}}^{m}$ ) and turbulent exchange $\left(S_{a_{f p}}^{t}\right.$ and $\left.S_{a_{m c}}^{t}\right)$, considering interfacial velocities.

\begin{tabular}{cccccc}
\hline $\mathrm{Q}_{\text {tot. }}(\mathrm{l} / \mathrm{s})$ & $\mathrm{X}(\mathrm{m})$ & \multicolumn{4}{c}{ Additional head losses (-) X 1000 } \\
\hline & & \multicolumn{2}{c}{ Floodplain } & \multicolumn{3}{c}{ Main channel } \\
\cline { 2 - 6 } & & $S_{a_{f p}}^{m}$ & $S_{a_{f p}}^{t}$ & $S_{a_{m c}}^{m}$ & $S_{a_{m c}}^{t}$ \\
\cline { 2 - 6 } 150 & 0 & 0.10 & -0.099 & 0.13 & 0.061 \\
& 2.5 & 0.89 & -0.001 & 1.13 & 0.001 \\
& 3.5 & 0.60 & -0.001 & 1.64 & 0.000 \\
260 & 4.5 & -1.65 & -0.000 & 0.91 & 0.000 \\
& 0 & 0.05 & -0.031 & 0.01 & 0.037 \\
& 2.5 & 1.94 & -0.000 & 0.41 & 0.000 \\
& 3.5 & 0.95 & -0.000 & 0.36 & 0.000 \\
& 4.5 & -1.39 & -0.000 & 0.22 & 0.000 \\
\hline
\end{tabular}




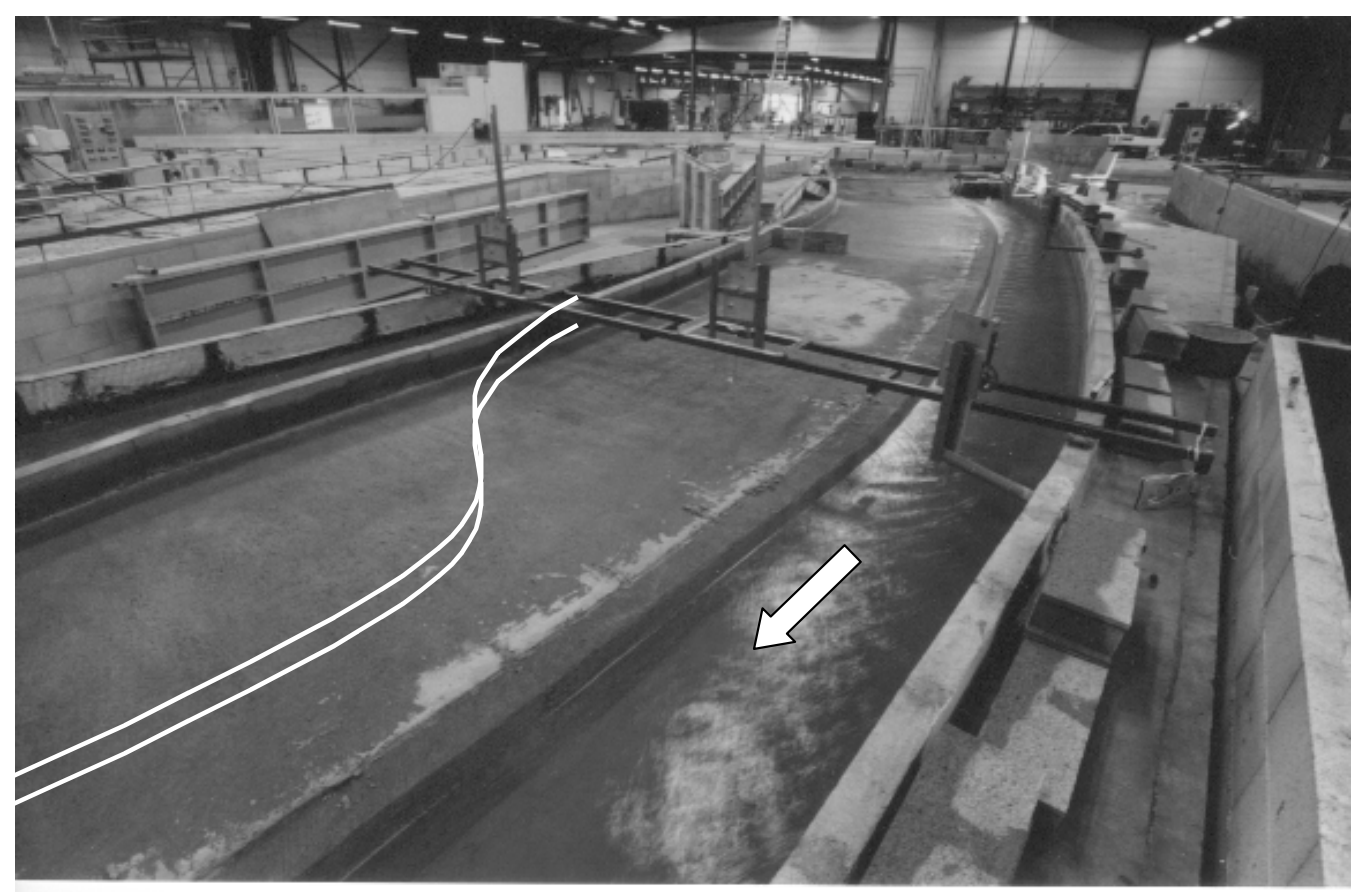

Fig. 1. Compound channel flume of the Compagnie Nationale du Rhône 


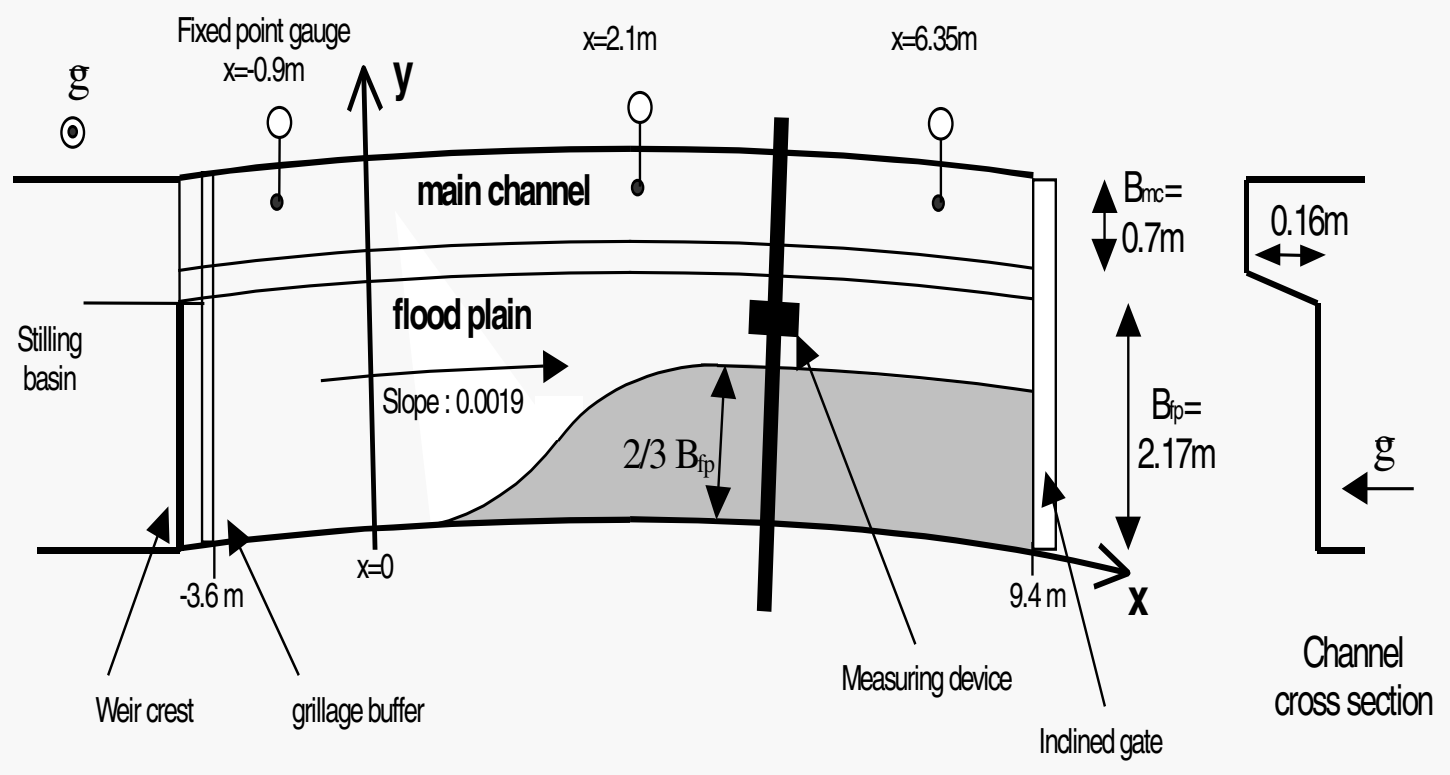

FIG. 2. Experimental setup scheme 


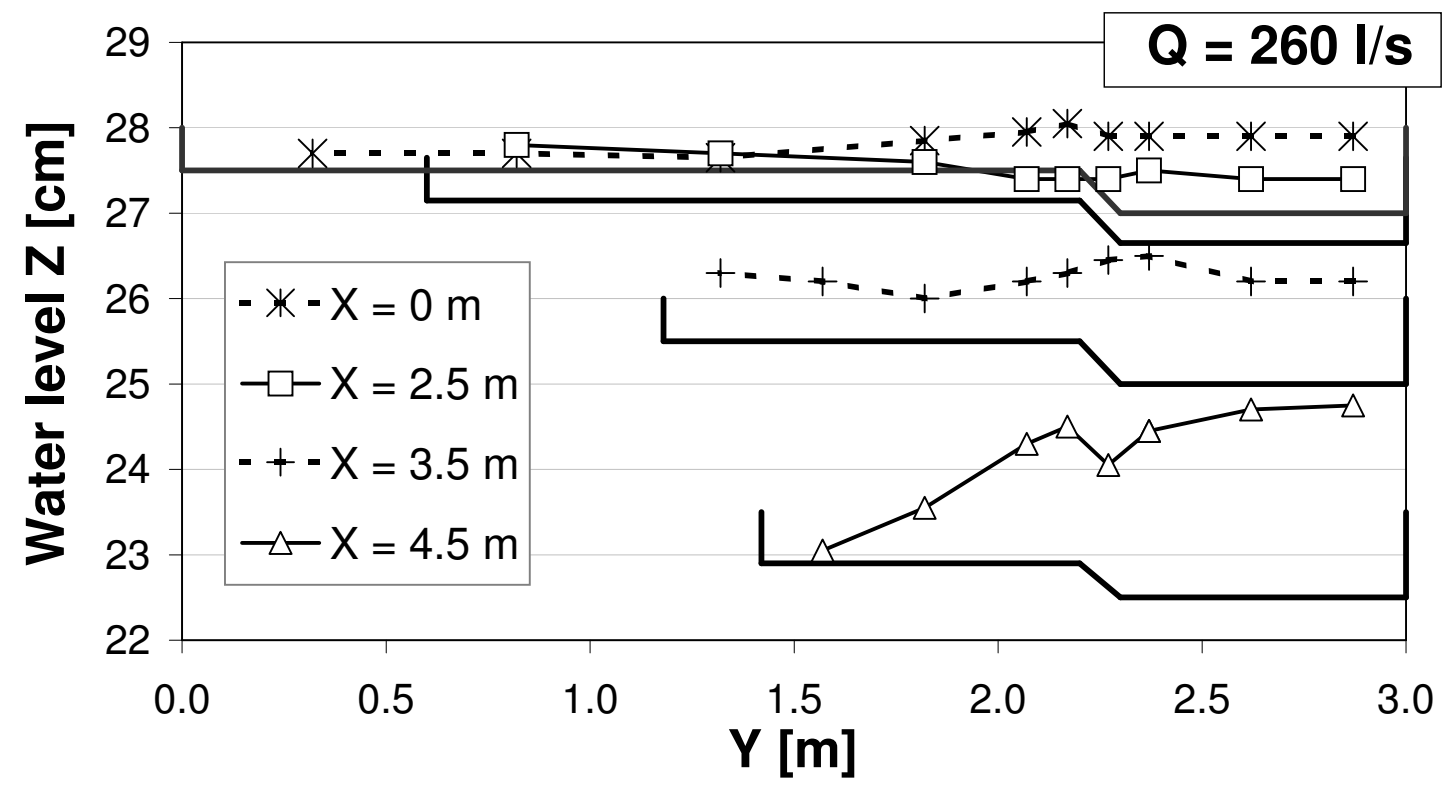

FIG. 3. Lateral profiles of water levels - Q $=260 \mathrm{l} / \mathrm{s}$ 

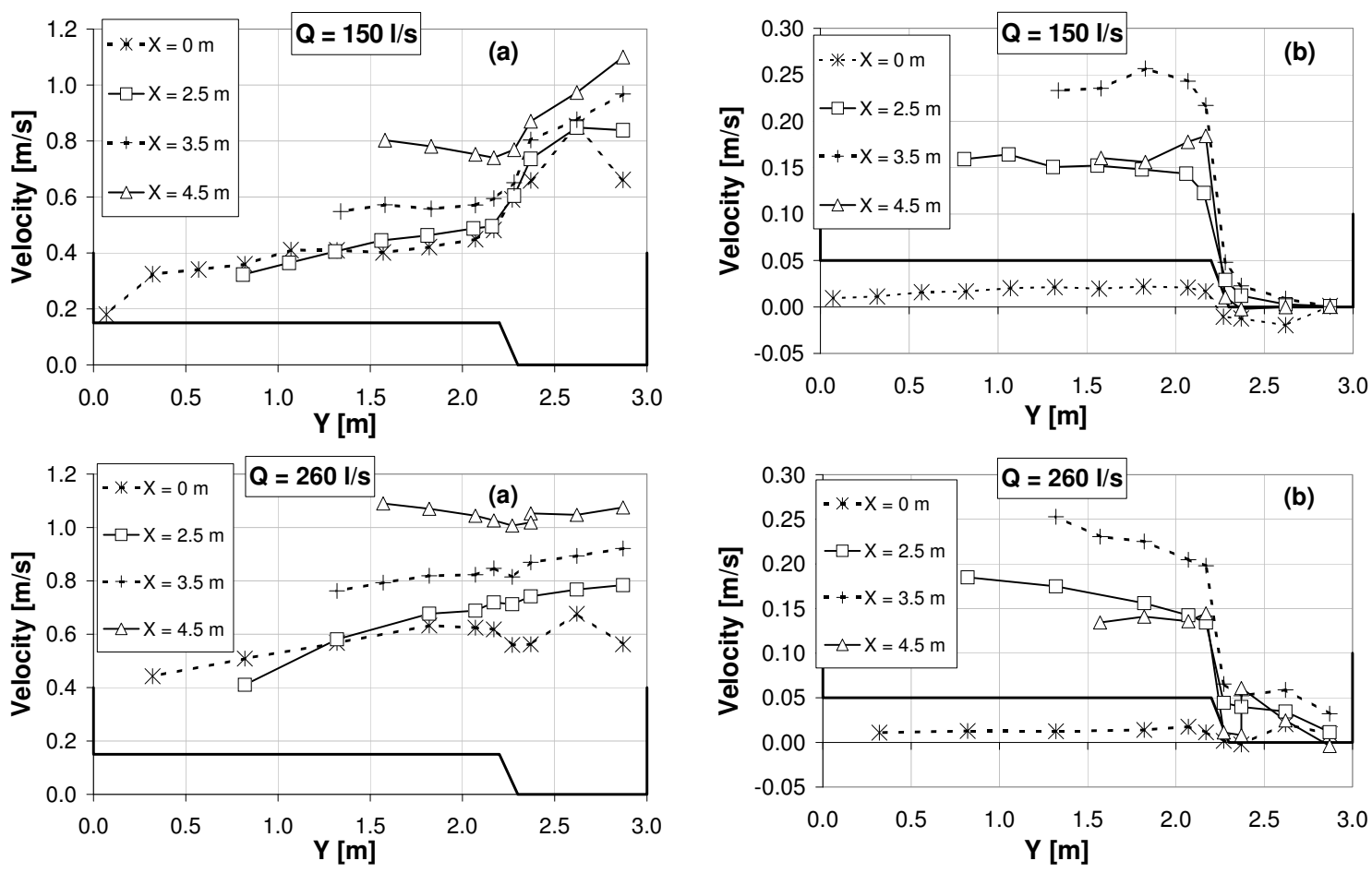

FIG. 4 - Lateral distributions of depth-averaged velocities: (a) longitudinal component $U_{d}$ and (b) transverse component, $V_{d}$. 


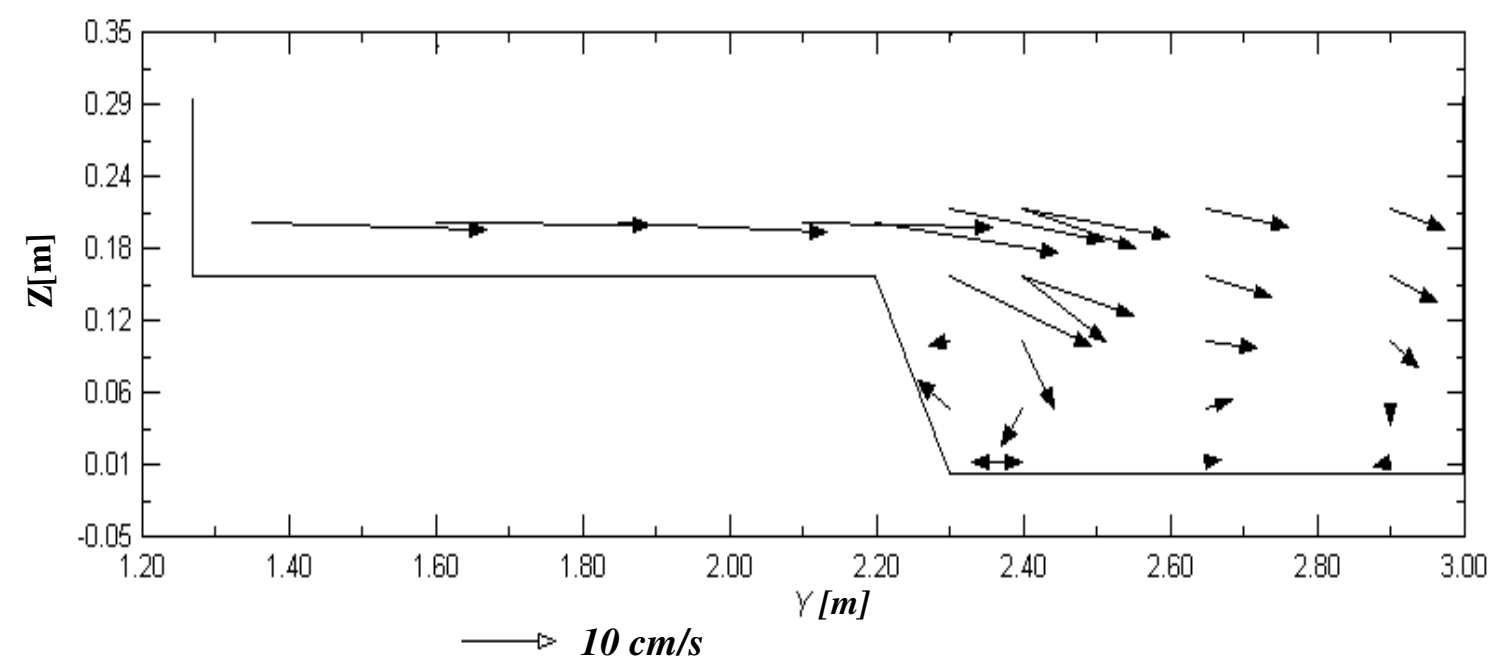

FIG. 5 - Velocities field in the vertical plane $x=3.5 \mathrm{~m}-\mathrm{Q}=260 \mathrm{l} / \mathrm{s}$ 


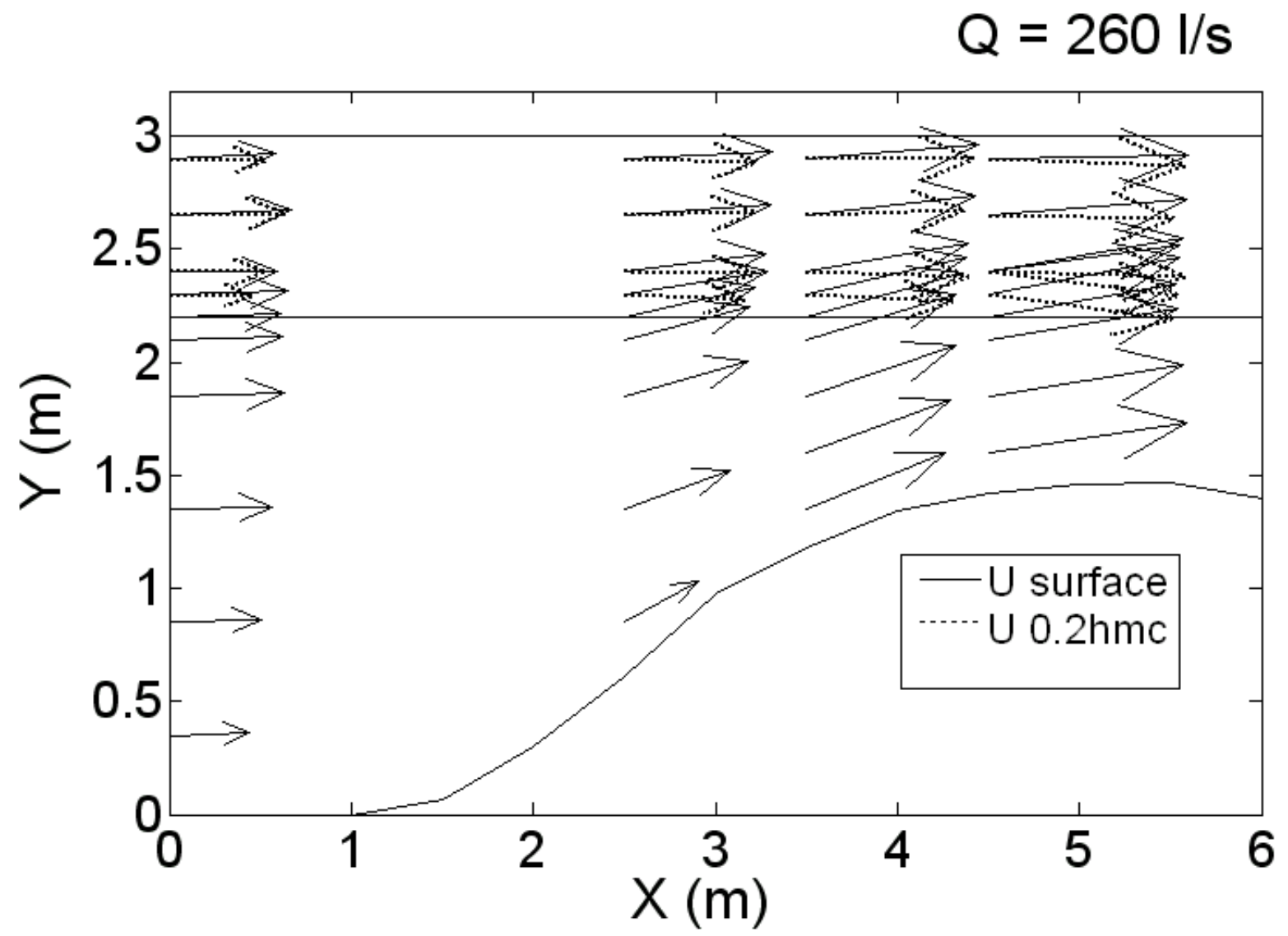

FIG. 6. Velocities field measured near the bottom $\left(0.2 \mathrm{~h}_{\mathrm{mc}}\right)$ and the surface $-\mathrm{Q}=$ $260 \mathrm{l} / \mathrm{s}$. 


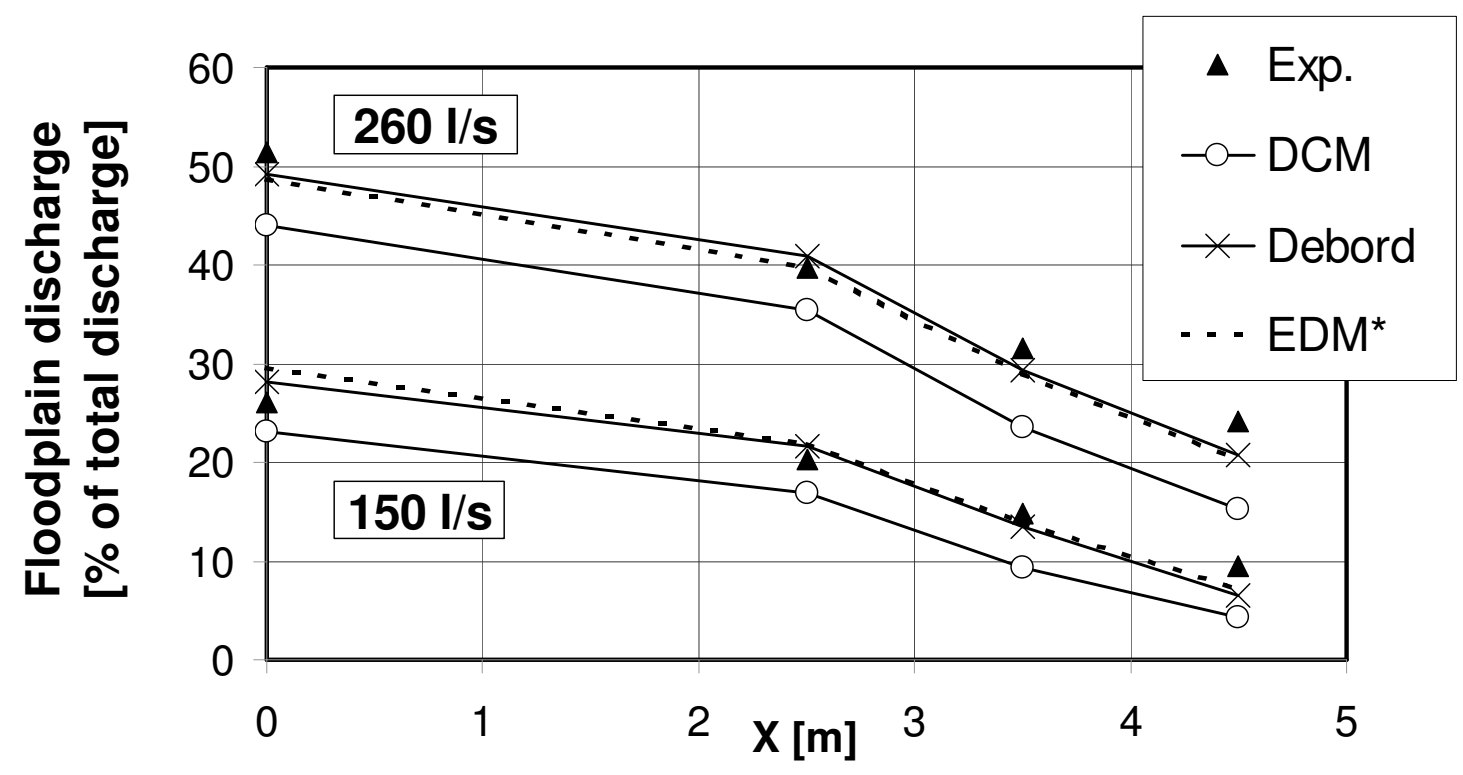

FIG. 7. Floodplain discharge as percentage of total discharge - calculations against data. 

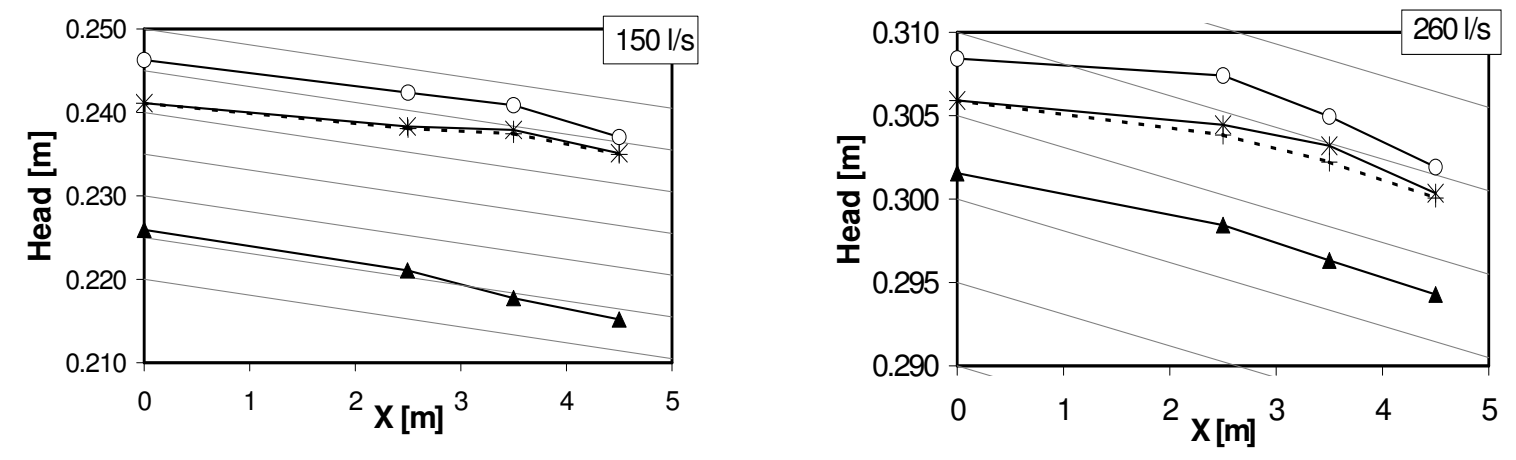

$\rightarrow$ Whole section $\left(\mathrm{u}^{2}+\mathrm{v}^{2}\right)-+\cdot$ Whole section $(\mathrm{u}) \longrightarrow$-Floodplain $\multimap-$ Main channel $\longrightarrow$ Bed slope

FIG. 8. Head profiles in the whole cross-section and in the subsections 

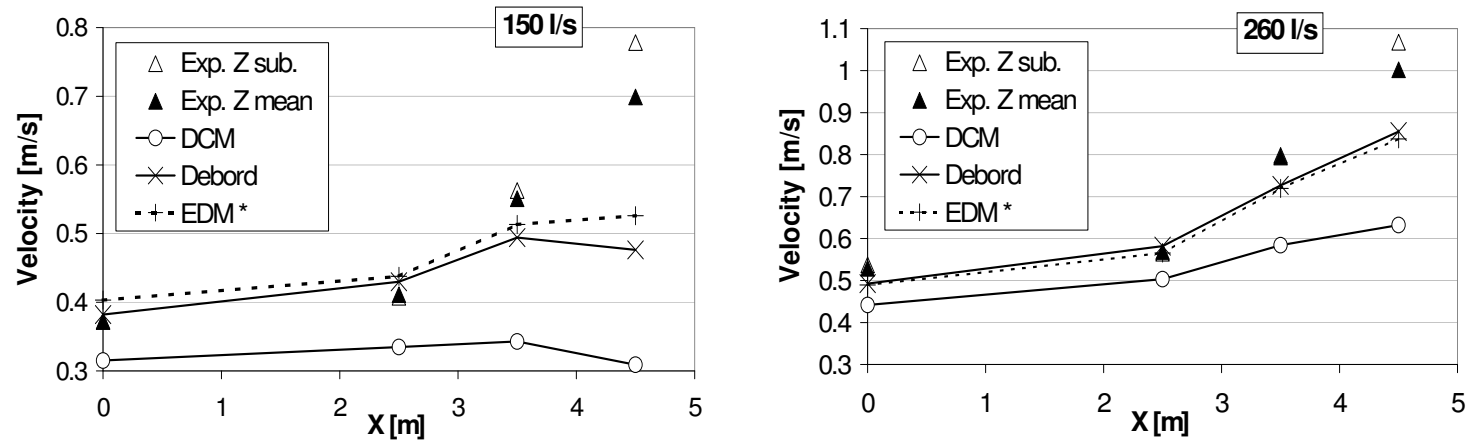

FIG. 9. - Evolution of the mean velocity in the floodplain 

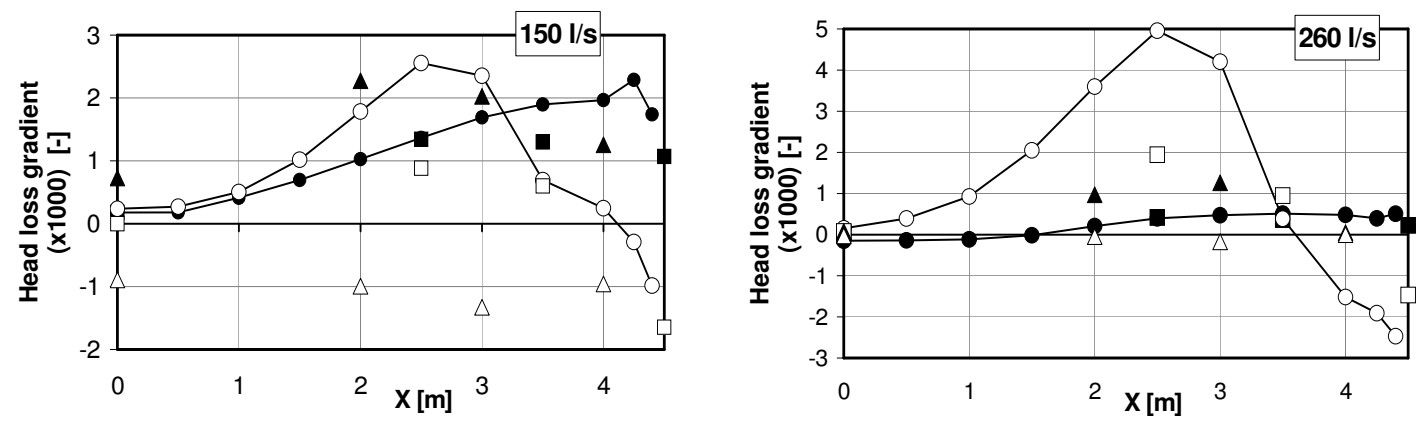

$\rightarrow-M C 2 D \quad \triangle M C 1 D \quad \square$ MC 1D Uint $-O-F P 2 D \quad \triangle$ FP1D $\quad \square$ FP 1D Uint

FIG. 10 - Experimental 1D additional head loss gradients $S_{a}$ and 2D computed ones $S_{a .2 D}$ in both subsections. 

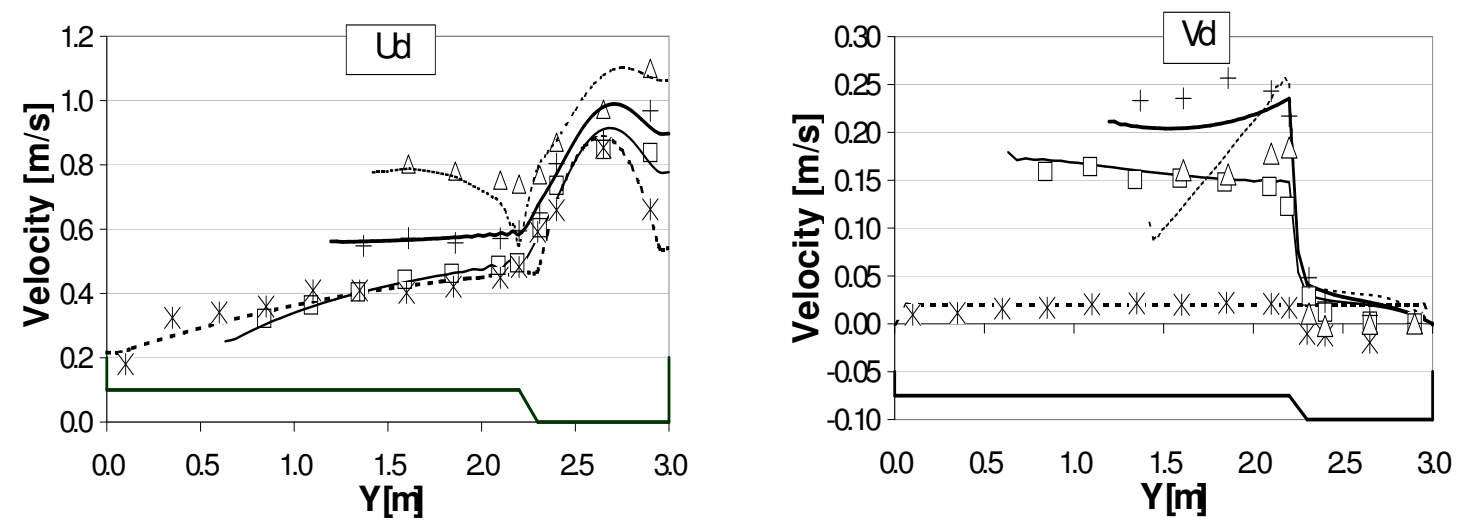

\begin{tabular}{|c|c|c|c|}
\hline$* X=0 m-$ Exp. & $\square X=2,5 m-$ Exp. & $+X=3,5 m-$ Exp. & $\Delta X=4,5 m-$ Exp. \\
\hline$-x=0$ & $\longrightarrow X=2.5 m-\operatorname{Mac} 2 \mathrm{D}$ & $\cdot X=3.5 m-\operatorname{Mac} 2 D$ & $\because \mathrm{X}=4.5 \mathrm{~m}-\mathrm{Mac} 2 \mathrm{D}$ \\
\hline
\end{tabular}

FIG. 11 - Distribution of velocity components, $U_{d}$, and $V_{d}$, computed by MAC $2 \mathrm{D}$ for $Q=150 \mathrm{l} / \mathrm{s}$. 


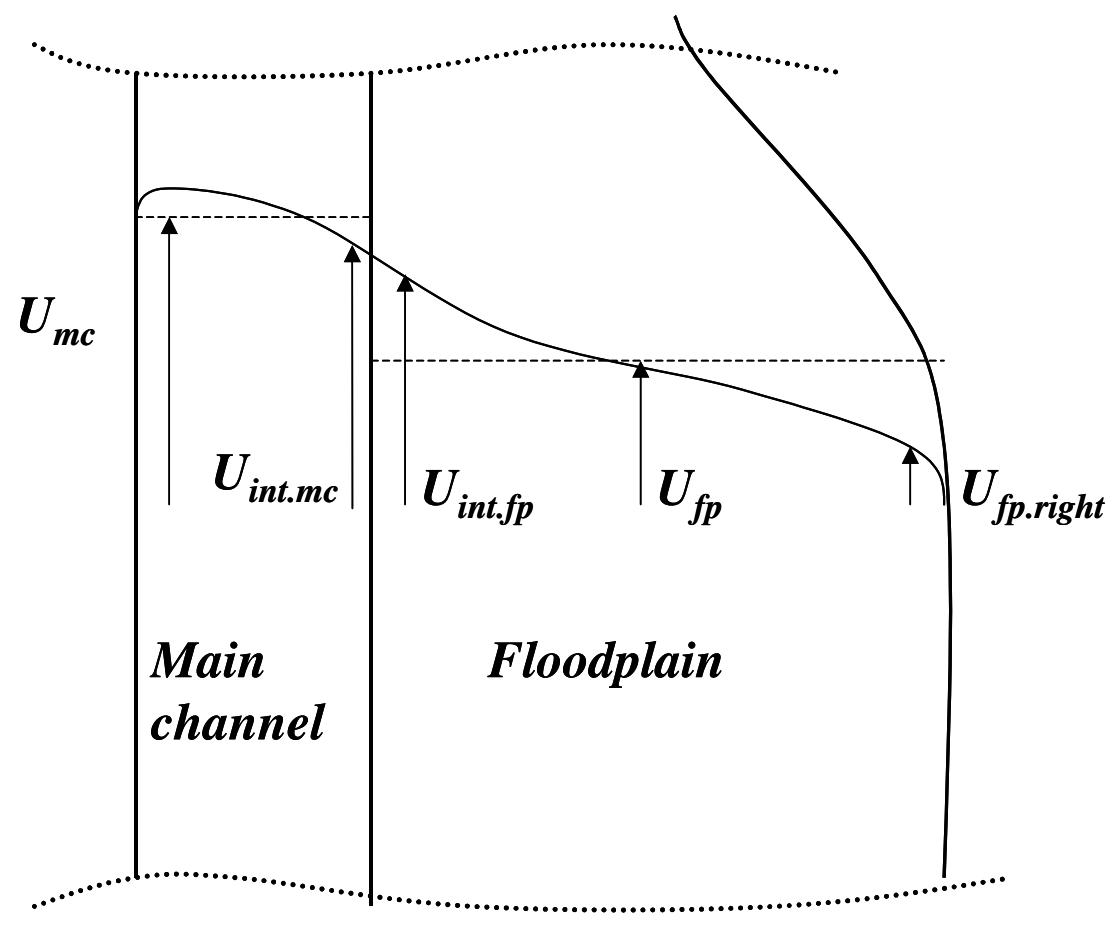

Fig. 12 - Schematic lateral profile of longitudinal depth-averaged velocity $U_{d}$ 

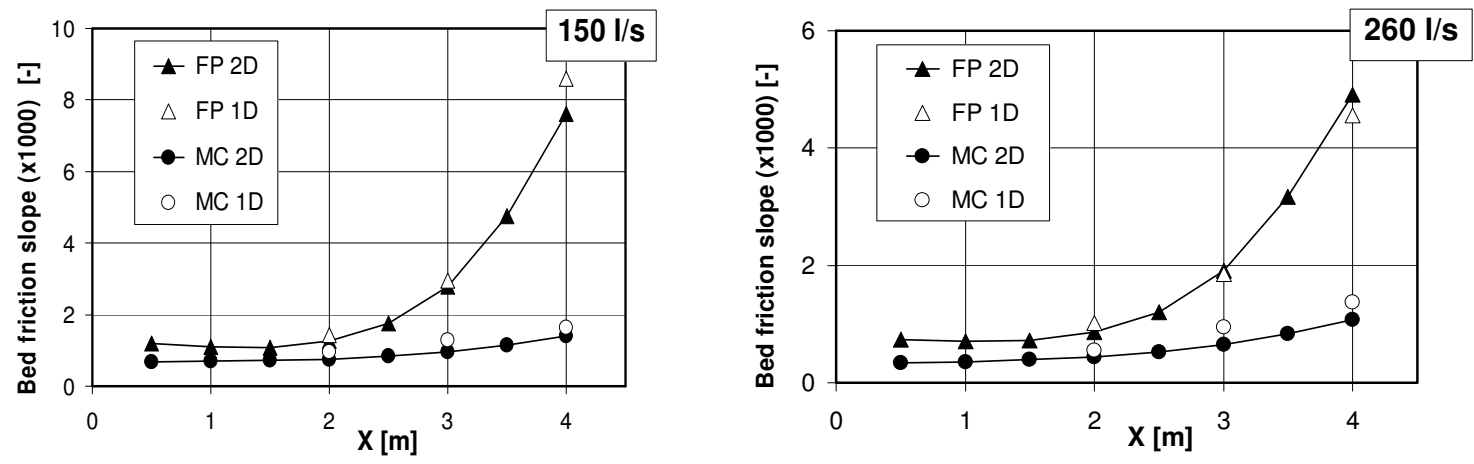

FIG. 13 - Experimental bed friction slope $S_{f}(1 \mathrm{D})$ and computed one $S f_{x}(2 \mathrm{D})$, in both subsections 

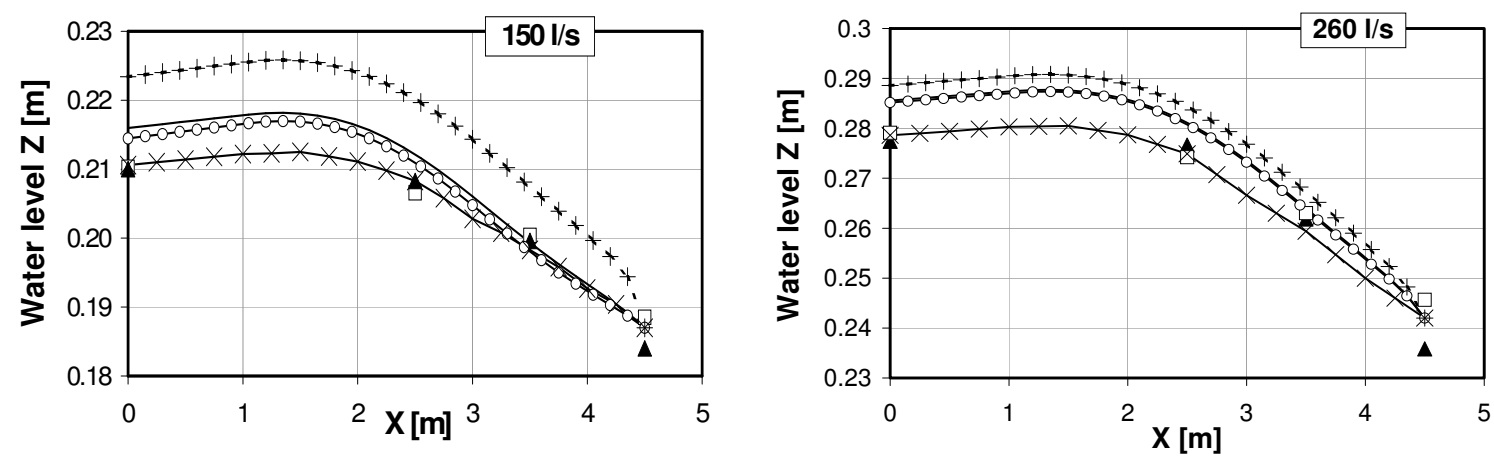
$\Delta \quad$ FP exp.
$\multimap \leftarrow$ Talweg-Fluvia (Debord)
-O-HEC-RAS (DCM)
$\square \quad M C$ exp.
$\longrightarrow$ Axerix $\left(\mathrm{EDM}^{*}\right)$
- + Axeriv (EDM)

FIG. 14 - Longitudinal water surface profiles - Calculation against experimental data. 

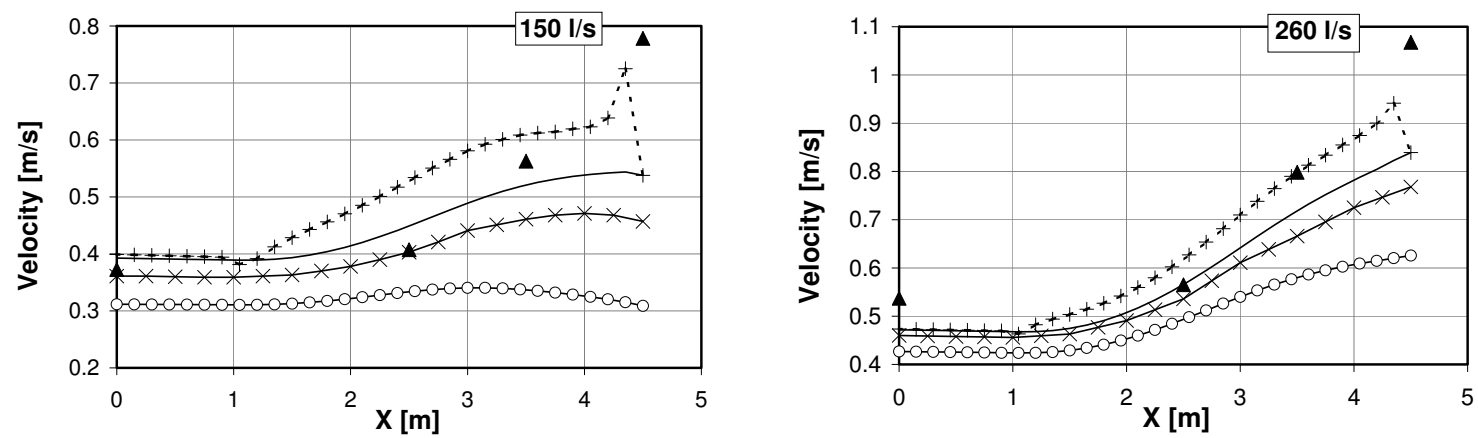

$\Delta$ Exp. -O-HEC-RAS (DCM) *Talweg-Fluvia (Debord) -Axeriv (EDM *) $\quad$ - Axeriv(EDM)

\section{FIG. 15 - Floodplain velocity profiles - Calculation against experimental} data. 